\title{
Chapter 6 \\ Remote Sensing for Early, Detailed, and Accurate Detection of Forest Disturbance and Decline for Protection of Biodiversity
}

\author{
Jennifer Pontius, Paul Schaberg, and Ryan Hanavan
}

\subsection{Introduction}

In many ways, biodiversity is a foundational component of healthy, productive forests and maintenance of the many ecosystem services that they provide (e.g., carbon sequestration, nutrient cycling, water filtration and provisioning, wildlife habitat). Forested landscapes are often characterized by a mosaic of species, age classes, and structural characteristics that results from natural patterns of disturbance. This diversity within stands and across forested landscapes increases resilience of larger forested ecosystems, enabling them to recover and maintain ecological function following disturbance (Thompson et al. 2009). But many pests and pathogens, particularly exotic invasive insects, as well as various abiotic stresses (e.g., pollution impacts or increases in climate extremes), have the potential to alter native populations, reduce biodiversity, and impact ecosystem function and service provisioning. This is particularly true for ecosystems dominated by keystone or foundational species, which exert a relatively large impact on community stability and ecosystem function (Ellison et al. 2010).

There are many examples of the impacts of pests and pathogens on biodiversity and ecological function in forested ecosystems. Dutch elm disease was introduced in the United States in the 1930s and the United Kingdom in the 1970s, with

\author{
J. Pontius ( $\bowtie)$ \\ Rubenstein School of Environment and Natural Resources, University of Vermont, \\ Burlington, VT, USA \\ USDA Forest Service, Northern Research Station, Burlington, VT, USA \\ e-mail: Jennifer.pontius@uvm.edu \\ P. Schaberg \\ USDA Forest Service, Northern Research Station, Burlington, VT, USA \\ R. Hanavan \\ USDA Forest Service, Forest Health Protection, Northeastern Area, Durham, NH, USA
}

J. Cavender-Bares et al. (eds.), Remote Sensing of Plant Biodiversity, 
Fig. 6.1 Ancient whitebark pines killed by the recent mountain pine beetle outbreak stand on a windy ridge in Yellowstone National Park. (Credit: Adam Markham/CleanAirCoolPlanet.org, https:// www.fws.gov/cno/ newsroom/highlights/2017/ whitebark_pine/)

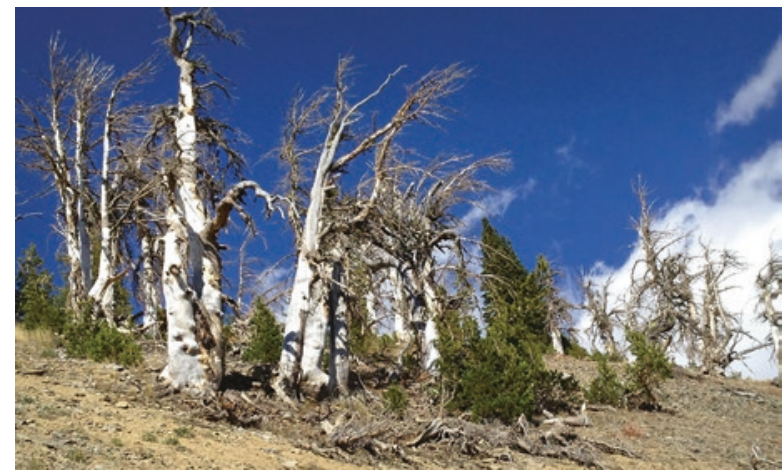

profound impacts on the biodiversity of rural landscapes (Harwood et al. 2011). The mountain pine beetle has impacted large swaths of coniferous and mixed forests in British Columbia, with severe impacts to avian biodiversity (Martin et al. 2006). In the western United States, pine blister rust has impacted biodiversity and ecological processes, particularly at high elevation sites where whitebark pine is a keystone species (Tomback and Achuff 2010, Fig. 6.1). Recent cases, such as the introduction of the Asian long-horned beetle and emerald ash borer to the United States, demonstrate the ongoing biosecurity challenges that currently face forested ecosystems.

Similarly, abiotic stresses can lead to declines that alter competition and biodiversity in the broader forest. For example, acid deposition that resulted from elevated inputs of sulfur and nitrogen pollution in the 1950s through 1980s led to declines in red spruce (Picea rubens Sarg.) (Schaberg et al. 2011) and sugar maple (Acer saccharum Marsh.) (Huggett et al. 2007) and increases in less sensitive species such as American beech (Fagus grandifolia Ehrh.) (Schaberg et al. 2001; Pontius et al. 2016). In another example, warming temperatures were associated with reductions in winter snowpacks, increased soil freezing, and root mortality that resulted in the broad-scale decline of yellow cedar (Callitropsis nootkatensis) but not sympatric species (Hennon et al. 2012). Warmer climates have also resulted in range expansion of native insects and disease with potential to further alter the landscape. For example, the southern pine beetle (Dendroctonus frontalis) continues to move north from the loblolly forests of the southern United States to pitch pine in the north.

Many resource managers cite the need for early detection of forest decline to minimize impacts of emergent stress agents (Genovesi et al. 2015; Sitzia et al. 2016). Research has shown that the earlier you can detect forest decline, the more successful management and control efforts will be (Epanchin-Niell and Hastings 2010). For invasive pests and pathogens, identifying the locations of incipient infestations is critical to minimizing spread, reducing ecosystem impacts, and targeting management and control (Mumford 2017).

But early detection also benefits the sustainable management of forested ecosystems responding to lower-level, chronic stress agents such as climate change and acid deposition. Such chronic stress agents often manifest in more subtle decline 
symptoms over many years. This slow and highly variable decline (some good years, some bad years) limits the ability to identify causal relationships, understand potential impacts to ecosystem function, and develop management strategies. As a result, we need to be able to quantify decline symptoms with greater detail and sensitivity to subtle changes, from the gradual loss of photosynthetic apparatus in response to initial stress, to reductions in canopy density, dieback, and ultimate mortality across the landscape.

Remote sensing (RS) has long been used to assess relative vegetation density, decline, and mortality. But landscape-scale assessment of small-scale or subtle decline symptoms has been more difficult. The spatial patial resolution of many sensors has limited our ability to detect small-scale decline in highly mixed pixels, while spectral resolution has limited our ability to detect early biogeochemical precursors to more severe decline symptoms. But as new sensors and modeling algorithms have come on board, there is a growing list of successful early decline detection efforts.

Here we present the science behind RS for the assessment of vegetation condition, with a focus on using these tools for more detailed and accurate monitoring of forest decline and disturbance. We also highlight the importance of this approach to inform the sustainable management of forested ecosystems and preservation of forest biodiversity.

\subsection{The Basics of Forest Decline}

In order to better understand how RS instruments can detect vegetation stress, and be used to quantify forest decline, it is important to understand the structural and physiological response of vegetation to stress. Any RS effort to detect or monitor decline is based on the sensor's ability to detect these biophysical changes that manifest following stress.

Trees adjust their physiology and form in response to environmental stimuli (e.g., light, temperature, moisture). Stress occurs when environmental conditions fall outside of the normal or optimal levels to which plants are adapted. As sessile organisms that cannot flee from the many stresses that they are routinely exposed to over their long life spans, trees have evolved enumerable mechanisms to avoid, mitigate, or rebound from stress. Some of these adaptations (e.g., protective pigments such as the yellow/orange carotenoids and red anthocyanins in leaves) can directly influence RS spectral measurements. Other stress adaptations (e.g., changes in carbohydrate storage and lipid and protein metabolism; Strimbeck et al. 2015) influence spectral characteristics indirectly through changes in leaf retention and life span. Here we walk through some of these physiological and structural changes relevant to RS efforts in more detail.

Leaf Size Small, emerging leaves can be difficult to detect via RS (e.g., White et al. 2014). Therefore, factors that delay or expedite bud break and leaf expansion, or lead to leaf wilting, curling, and folding can influence spectral signatures 
Fig. 6.2 Leaf curl, wilt, and stunted expansion can result in decreased leaf area index that is commonly quantified in RS applications. (Credit: Eiku [CC BY-SA 4.0] from Wikimedia Commons)
Fig. 6.3 Many sensors can detect changes in leaf pigment concentration and function before chlorosis is visible to the human eye. (Credit: [CC0] https:// pxhere.com/en/ photo/575928)
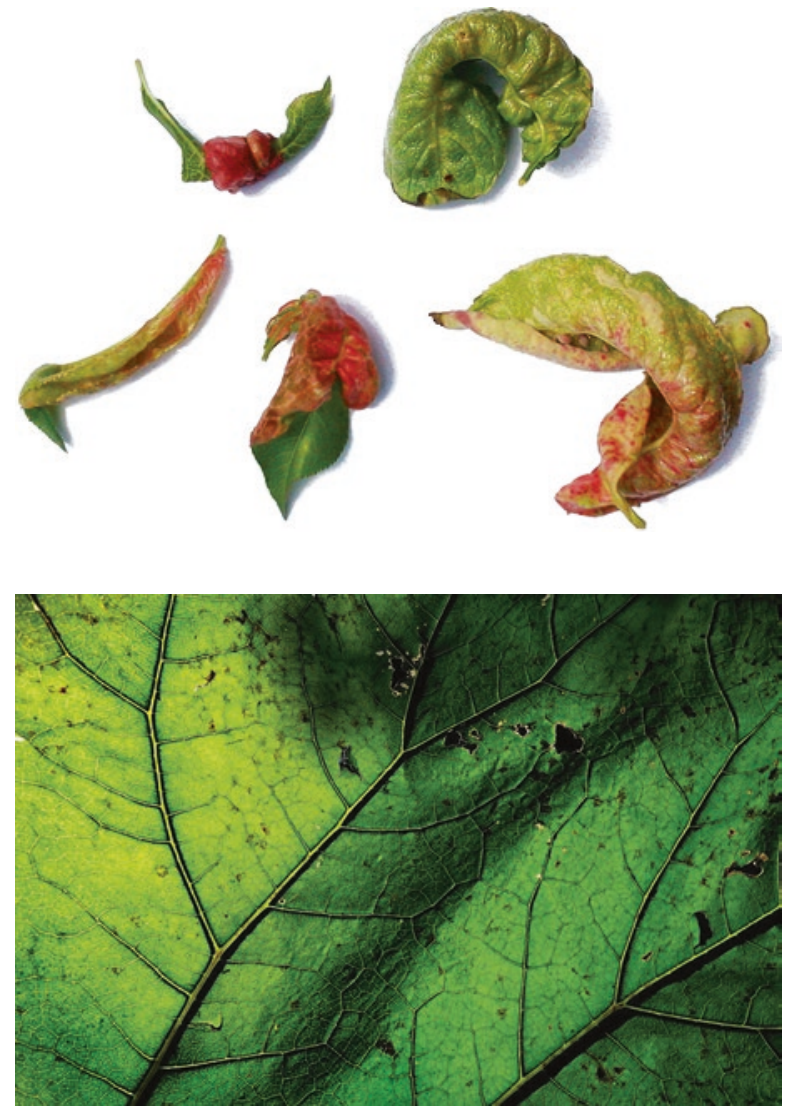

(Fig. 6.2). In addition, leaves that develop after episodic leaf mortality are often stunted, diminishing overall leaf area. Reduced leaf size can also result from carbohydrate losses associated with sucking insects, e.g., pear thrips (Taeniothrips inconsequens; Kolb and Teulon 1991), and insect herbivory can reduce the functional area of leaves through leaf consumption.

Leaf Chemistry and Physiology Plant pigments (chlorophylls essential in photosynthesis, xanthophylls that assist with light capture and protect leaves from photooxidation, and anthocyanins that have numerous protective capacities) are all spectrally responsive (Fig. 6.3). Therefore, environmental factors that influence their development and turnover (e.g., cold temperatures that can speed chlorophyll catabolism and trigger anthocyanin expression; Schaberg et al. 2017) can influence associated spectral signatures. Similarly, because leaf water content and chemistry have identifiable spectral features, environmental factors such as droughts, fertilization, and soil acidification can also influence spectral signatures.

Leaf Quantity and Longevity Despite remarkable and diverse capacities for stress response and protection, numerous biological and abiotic factors can reduce 
Fig. 6.4 Peeling back the bark on green ash shows the girdling effect of the emerald ash borer (Agrilus planipennis). (Credit: USDA Forest Service)

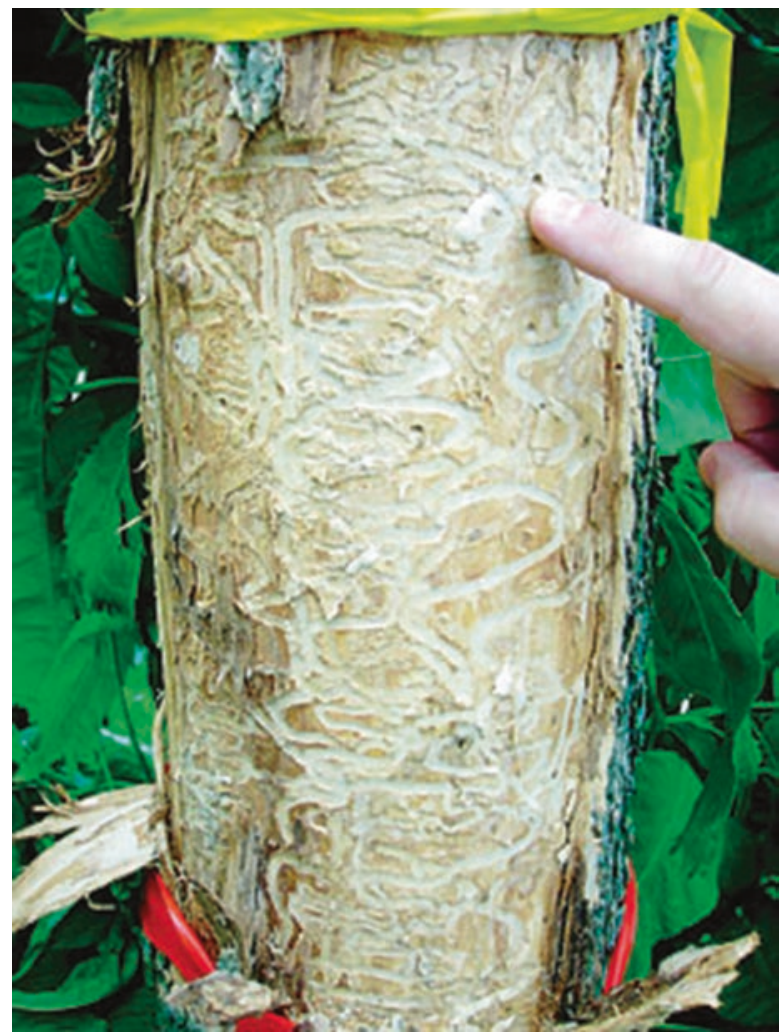

leaf longevity or lead to significant defoliation. The most prominent factors causing foliar reductions vary across ecoregions (e.g., drought is a dominant factor in the western United States, whereas insect defoliation is prominent in the eastern states) and over time (e.g., episodic drought, cyclic insect outbreaks). However, numerous anthropogenic factors (e.g., ozone pollution, acid deposition, introduction of exotic pests and pathogens) have expanded the list of stress agents that can lead to significant defoliation. Some stress agents directly result in defoliation, but many stress agents impact other organs that crowns rely on, for example, insects such as bark beetles and the emerald ash borer (Fig. 6.4) and pathogens such as chestnut blight girdle stems. Invasive pests such as hemlock woolly adelgid extract photosynthate directly from phloem. Root freezing injury (e.g., yellow cedar decline; Hennon et al. 2012) can limit resource uptake. All of these stress agents can manifest as reduced leaf area index and canopy density.

Branch Dieback, Tree Decline, and Mortality Repeated or severe direct damage to tree canopies or chronic imbalances in tree carbohydrate and/or stress response systems can lead to branch dieback. This dieback is typically first evident as mortality of the most distal portions of the crown (tip dieback) and can lead to significant carbon imbalances as the photosynthetic capacity of trees is outstripped by 
Fig. 6.5 Dieback typically results in changes to spectral characteristics as pixels become dominated by understory or bark and soil surface features. (Credit: Joseph O'Brien, USDA Forest Service, Bugwood.org)

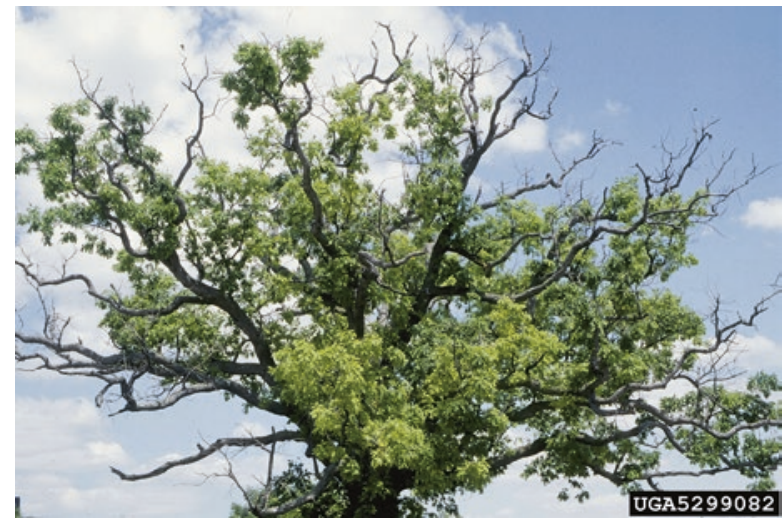

carbohydrate use associated with maintenance respiration as well as compensatory growth (e.g., epicormic branching), and seed production, which are often associated with decline. Significant crown loss exacerbates negative carbon balances, ultimately resulting in tree mortality. Temporary or partial crown dieback may be difficult to detect if it is not widespread, but protracted dieback, especially if it results in significant tree mortality, could dramatically alter spectral measurements in the near (during the decline event) and long terms if elevated mortality leads to significant changes in canopy density, gap fraction, species composition, or forest cover (Fig. 6.5).

\subsection{RS Approaches to Forest Decline Detection}

Aerial Sketch Mapping In the United States, federal and state forestry agencies have been conducting aerial detection surveys of forest decline for many decades (Fig. 6.6; Johnson and Wittwer 2008; Johnson and Ross 2008; McConnell 1999). This manual RS technique involves an observer mapping polygons by identifying host trees by crown shape and causal agent by damage signature from an aircraft. In the early decades (1950s-1980s), this was often deployed only in response to severe or widespread forest disturbance events, with limited flight lines and rough delineation of impacted stands onto paper maps. Now, organized by the national Forest Health Monitoring (FHM) program, many states are flown in their entirety each year to survey impacts from a suite of potential biotic and abiotic stressors and various disturbance types (e.g., defoliation, mortality, dieback), with mapping captured on digital, global positioning system (GPS)-enabled touchscreen tablets. Like other RS methods, ground validation adds confidence in the final map products. Aerial sketch mapping is currently the most widespread approach to forest condition mapping across the United States, and because of direct cooperation among federal and states agencies collecting and using the resulting maps, it also has the most direct link to land managers and decision-makers. 
Fig. 6.6 Cessna 170-B survey plane mapping Douglas-fir beetle damage near Sutherlin, Oregon. (Credit: USDA Forest Service, Region 6, State and Private Forestry)

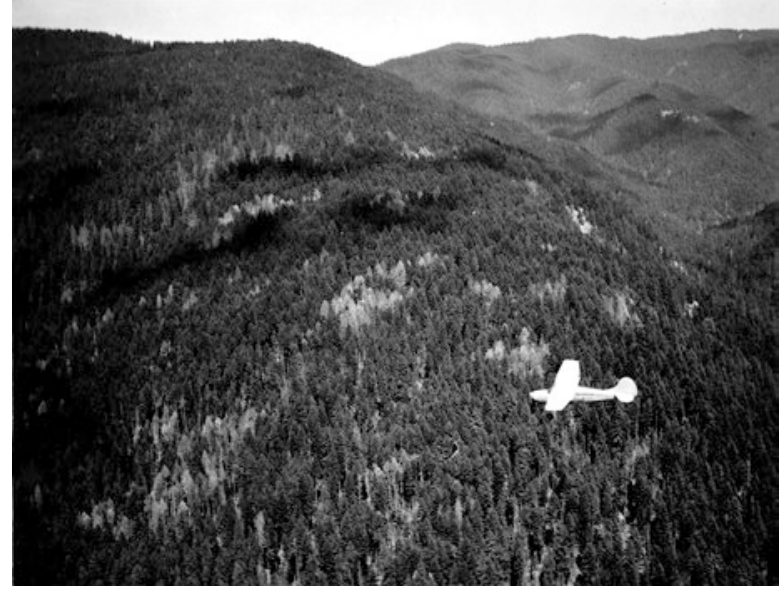

However, the mapping products generated vary based on differences in the base map scale used, observer bias, or agency emphasis (Kosiba et al. 2018). Products also vary year to year based on timing of flight and the visibility of different stress symptoms (e.g., early season vs. late season defoliators). Further, only decline symptoms that are severe enough, and in large enough patches to be visible to an observer in an aircraft traveling approximately 100 knots from an altitude of 1000-3000 feet above ground level, are mapped. As such, aerial sketch mapping can be highly subjective and should only be regarded as a coarse "snapshot" of landscape-level forest health.

Multispectral Sensors Terrestrial satellite RS began with the launch of the Landsat mission (then called the Earth Resources Technology Satellite (ERTS)) in 1972. Designed to supply regular images of Earth's surface, with multispectral bands designed to capture biospheric processes at medium-high spatial resolution, Landsat-1 enabled a revolution in terrestrial research (Williams et al. 2006). With continuous coverage since the 1972 launch, the family of Landsat sensors is particularly useful for studying forest change over time across regional to global scales (Fig. 6.7).

Initially, the broad, multispectral bands on the Landsat sensors were used to assess relative vegetative density, or "greenness." This was made possible by targeting the near-infrared (NIR) portions of the electromagnetic spectrum in addition to visible wavelengths. This "near-infrared plateau" is a region of strong reflectance in vegetation and is distinct from many other surface features such as soil, rock, and water, making it particularly useful for distinguishing vegetation from non-vegetative land cover types or assessing the relative amount of vegetation within mixed pixels. It is also highly responsive to common stress symptoms such as defoliation, chlorosis, and decreases in canopy density. Over the decades, scientists have developed a suite of vegetation indices to quantify vegetation condition and biophysical attributes (Table 6.1) that have been commonly used to assess changes in canopy cover (e.g., deforestation) and widespread defoliation or mortality. 


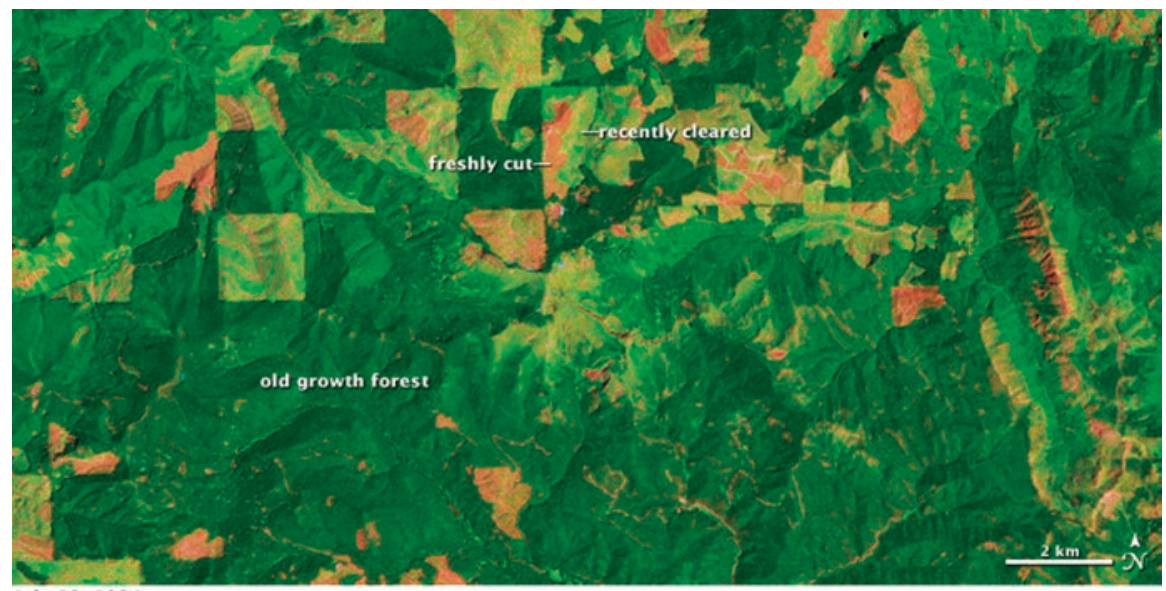

July 19, 1984

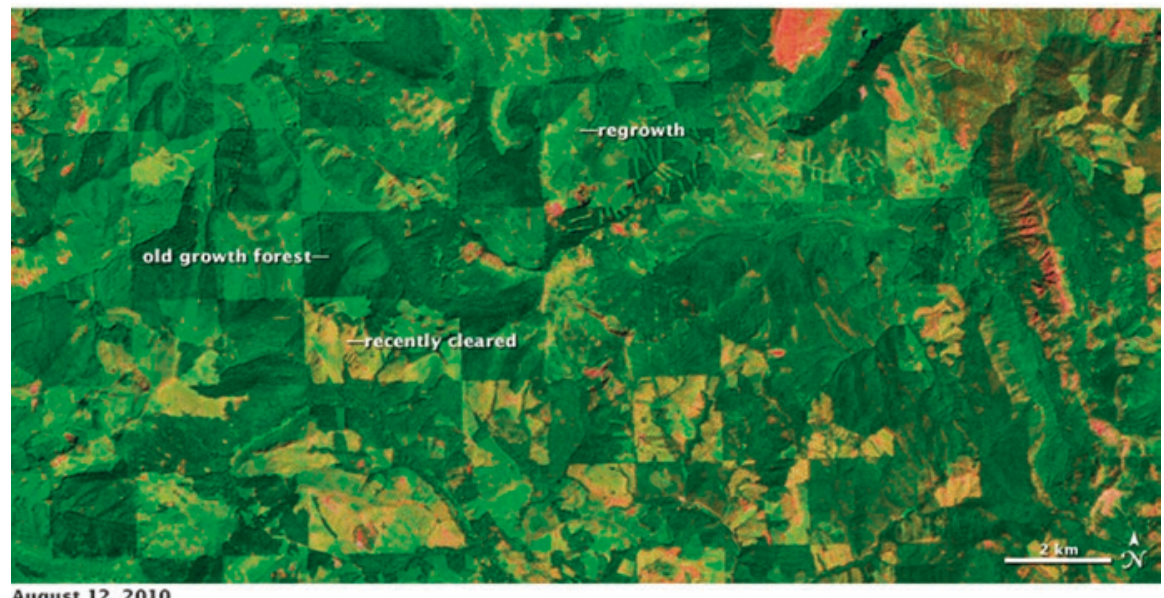

August 12, 2010

Fig. 6.7 Landsat images from 1984 and 2010 show clear-cutting and forest regrowth in Washington State, highlighting the utility of multispectral sensors in detecting vegetation density and disturbance. (Credit: NASA image by Robert Simmon)

The use of multispectral sensors to identify more subtle or early decline symptoms is typically limited by the spectral resolution (few, broad-bands of spectral information to work with), spatial resolution (mixes of healthy and stressed vegetation in one pixel often mask the spectral stress signature of stressed individual trees), and temporal resolution (inability to acquire cloud-free images at intervals sufficient to detect change).

As the interest in RS products has grown, along with the range of applications, many commercial vendors have expanded access to multispectral products with both aerial and satellite platforms. We now have over 100 active satellite sensors with visible and NIR capabilities listed in the International Inst. for Aerospace Survey and Earth Sciences (Netherlands; formerly International Training Centre for 


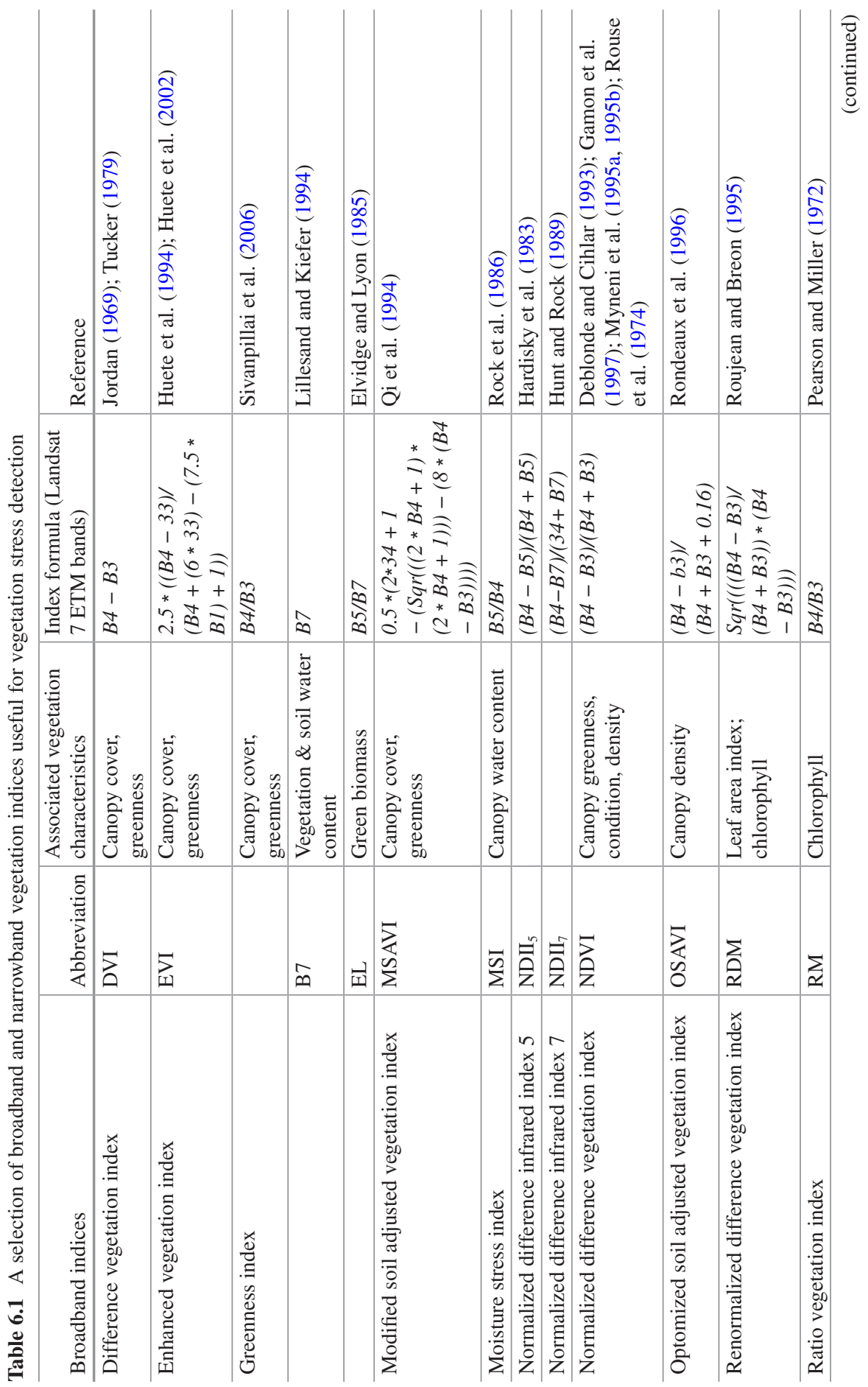




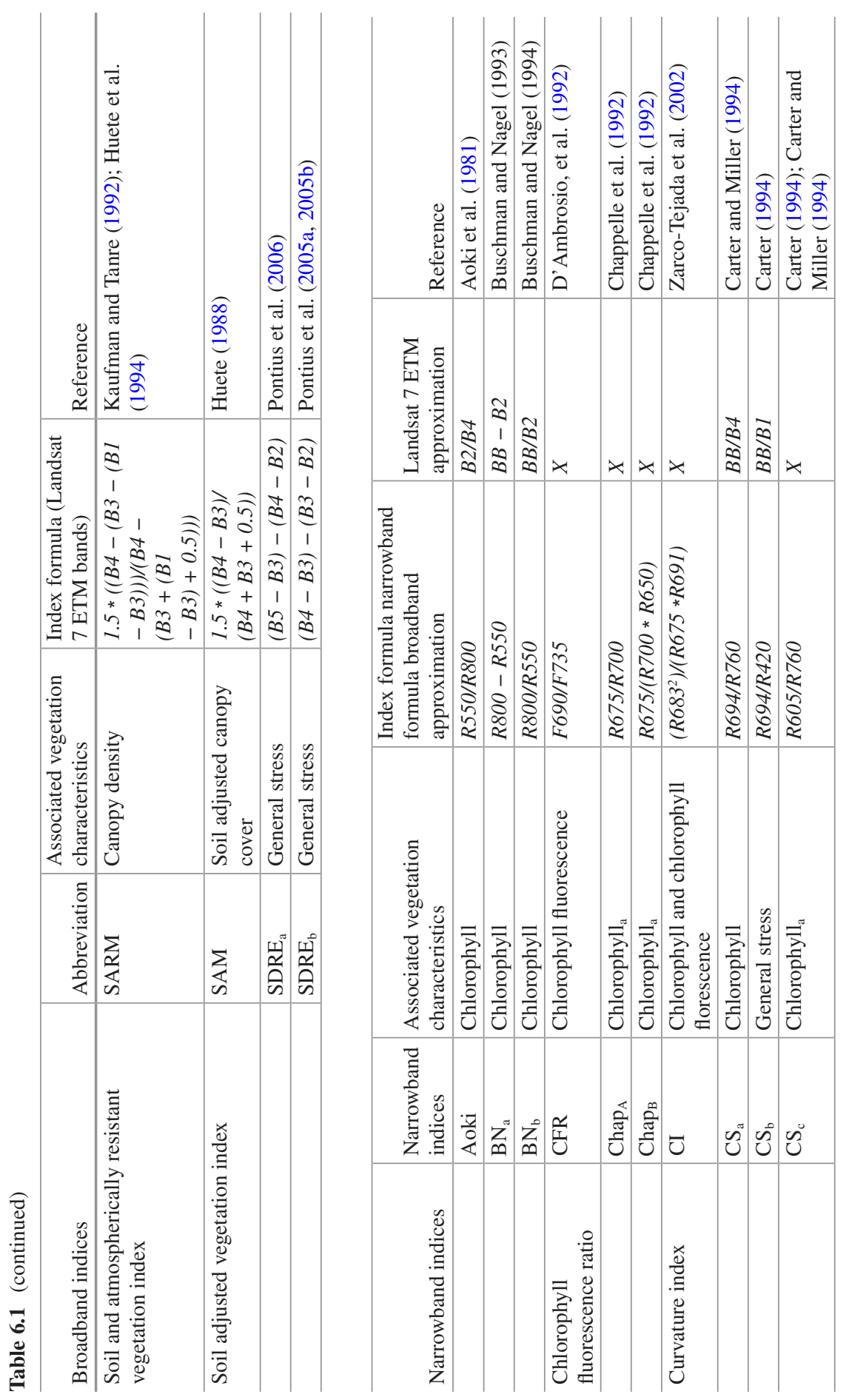




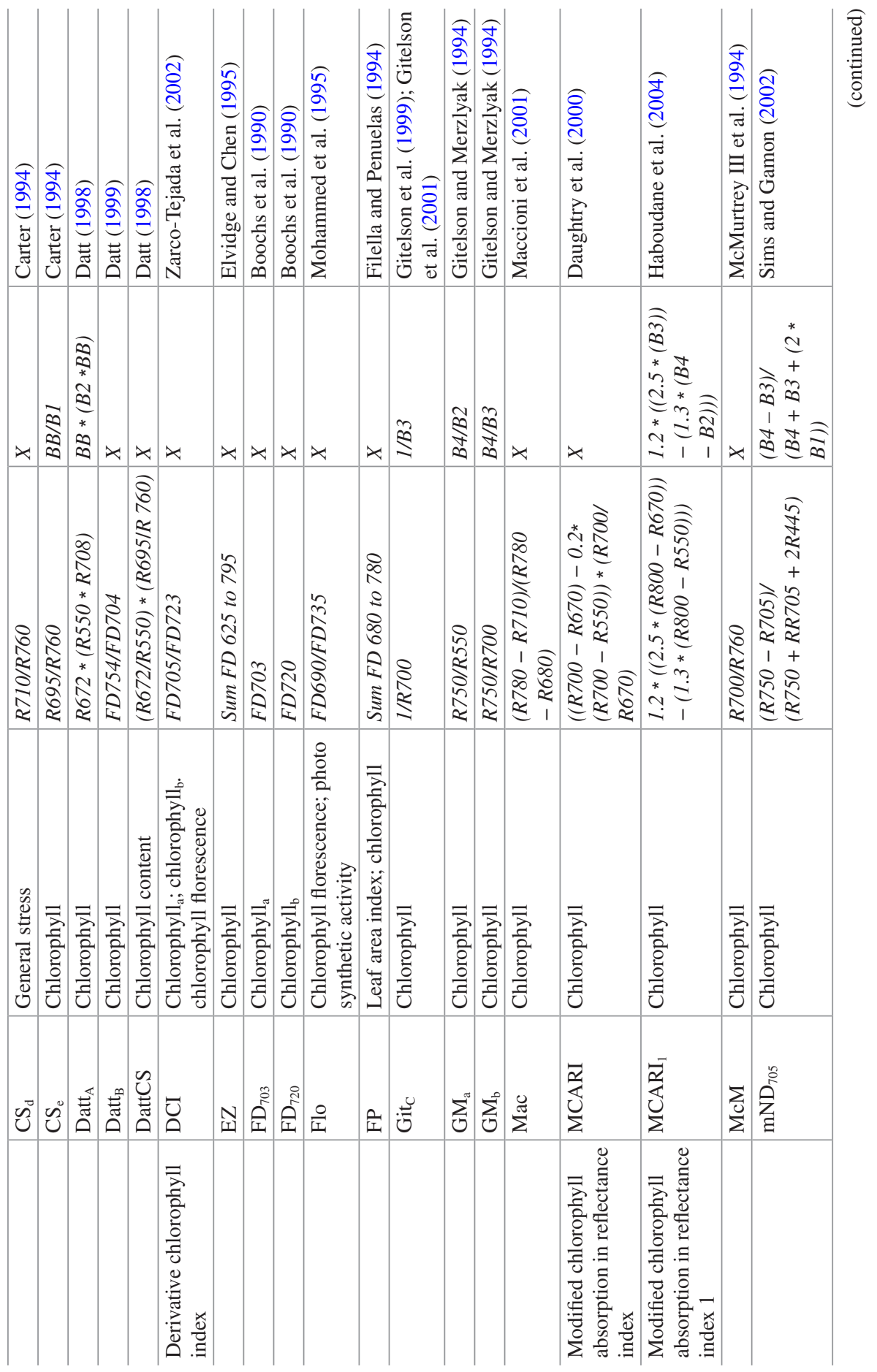




\begin{tabular}{|c|c|c|c|c|c|c|c|c|c|c|c|}
\hline 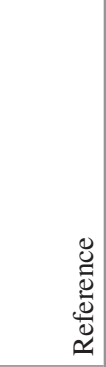 & 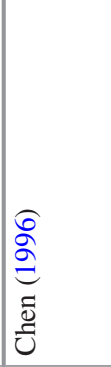 & 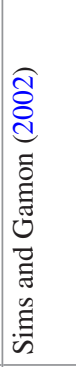 & 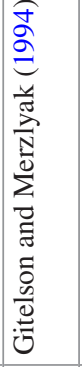 & 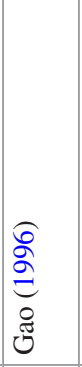 & 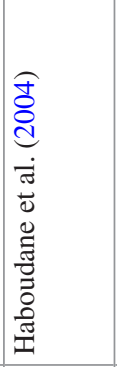 & 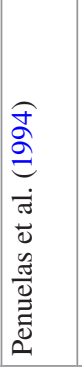 & 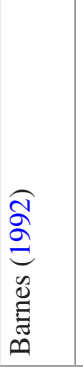 & 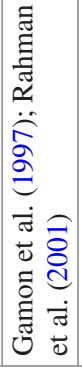 & 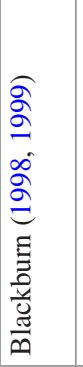 & 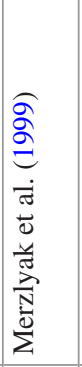 & 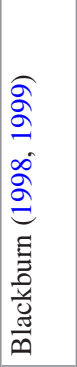 \\
\hline 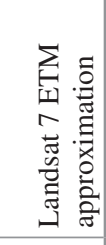 & 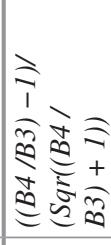 & 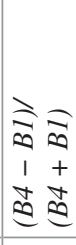 & $\begin{array}{cc}\widehat{\lambda} & \widehat{n} \\
0 & 0 \\
1 & 1 \\
5 & y \\
0 & 0\end{array}$ & 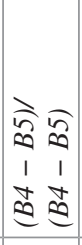 & 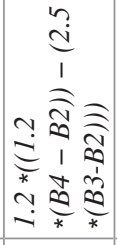 & 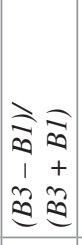 & $x$ & $x$ & $\begin{array}{ll}\widehat{㐅} & \widehat{0} \\
0 & 0 \\
1 & + \\
4 & 4 \\
0 & 0\end{array}$ & & 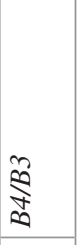 \\
\hline 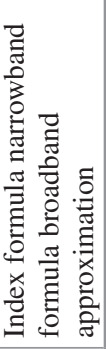 & 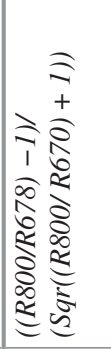 & 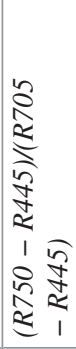 & 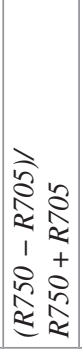 & 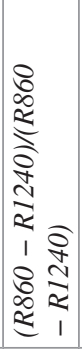 & 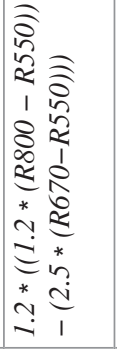 & 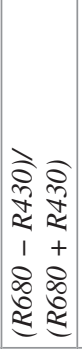 & 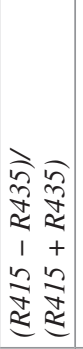 & 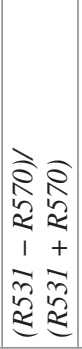 & 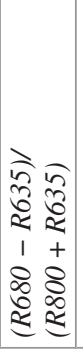 & 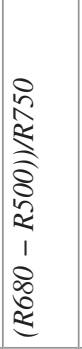 & \begin{tabular}{l}
$n$ \\
$\tilde{6}$ \\
\multirow{2}{n}{} \\
$\delta$ \\
$\infty$ \\
$\infty$ \\
2
\end{tabular} \\
\hline 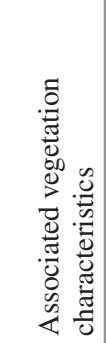 & 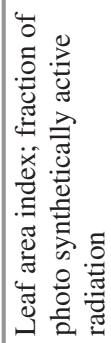 & 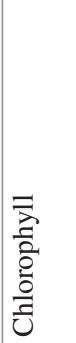 & 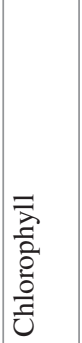 & 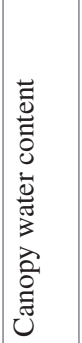 & 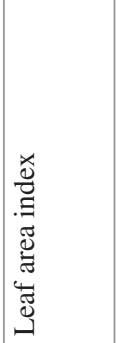 & 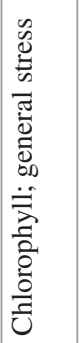 & 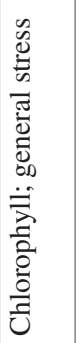 & 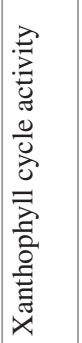 & 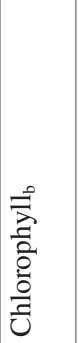 & 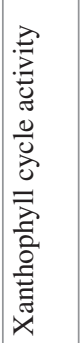 & 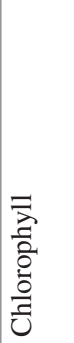 \\
\hline 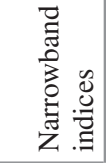 & $\frac{\pi}{\tilde{n}}$ & 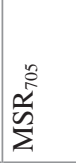 & $\overline{\mathrm{z}}$ & 之 & $\stackrel{s}{\Sigma}$ & $\begin{array}{l}\text { 己̈ } \\
\text { Z }\end{array}$ & $\begin{array}{l}\vec{\alpha} \\
\dot{z}\end{array}$ & $\overrightarrow{\widetilde{a}}$ & $\overbrace{\tilde{\omega}}$ & $\begin{array}{l}\vec{w} \\
\tilde{\alpha}\end{array}$ & $\begin{array}{l}\tilde{v} \\
\tilde{2} \\
\tilde{2}\end{array}$ \\
\hline 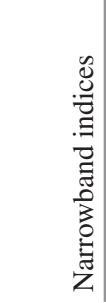 & 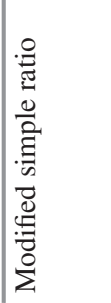 & 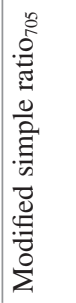 & 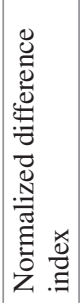 & 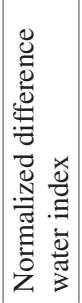 & 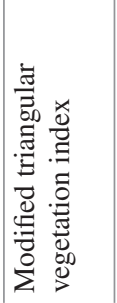 & 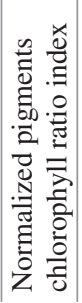 & 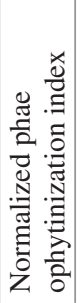 & 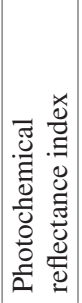 & 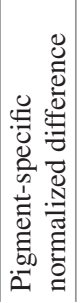 & 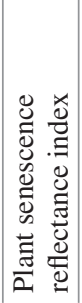 & 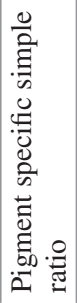 \\
\hline
\end{tabular}




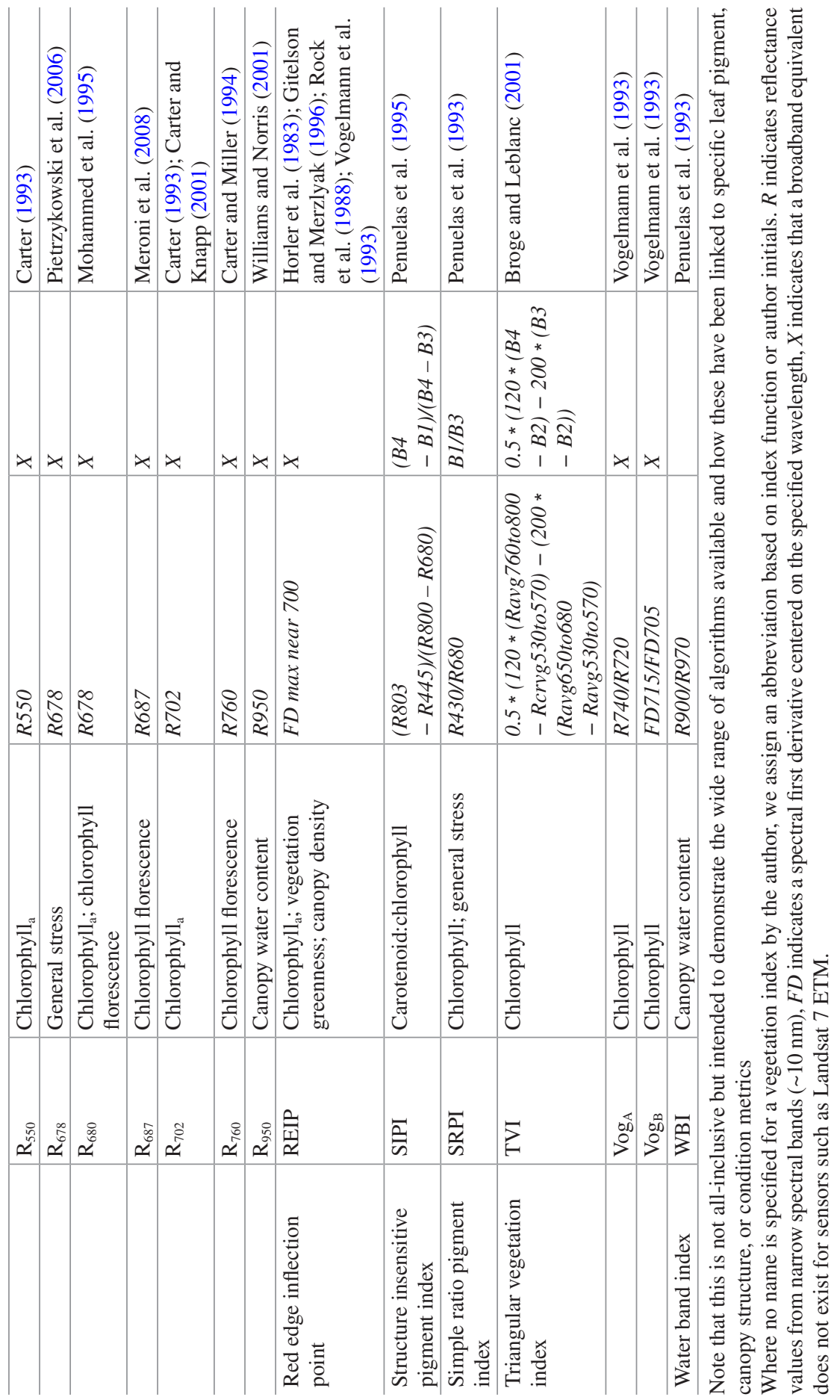


Aerial Survey) ITC Satellite and Sensor Database: https://webapps.itc.utwente.nl/ sensor/default.aspx?view=allsensors

One particularly promising sensor for improved forest health detection includes Sentinel 2 (A and B), recently launched by the European Space Agency. This is the first civil Earth observation sensor to include three bands in the red edge, providing additional information to quantify vegetation condition. Its 5-day repeat time and $10 \mathrm{~m}$ pixels also improve its ability to detect more subtle decline symptoms. This temporal resolution has proven useful in identifying forest decline based on detecting changes in the spectra of declining trees relative to healthy ones over time (Zarco-Tejada et al. 2018). Geostationary sensors like the GOES-R series also provide a unique opportunity to monitor forest condition at rapid time intervals across large landscapes. With two visible and four infrared bands useful to inform vegetation condition, the Advanced Baseline Imager on GOES-16 can provide images every 5 minutes with a spatial resolution of $0.5-2 \mathrm{~km}$.

Improvements in computing technologies and modeling techniques have also increased the utility of multispectral sensors in early vegetation decline detection (Lausch et al. 2017). For example, Pontius (2014) demonstrated that using a multitemporal approach mimicking hyperspectral algorithms could successfully quantify a detailed decline scale using Landsat TM data. Over time, ongoing improvements in sensor resolution, computing capabilities, and modeling options will enable measurements of more subtle changes in reflectance associated with early decline detection.

Hyperspectral Sensors While multispectral sensors record electromagnetic radiation averaged over a broad "band" of wavelengths, a hyperspectral instrument records many adjacent narrow bands to image most of the spectrum within a set range. What makes these instruments so useful for vegetation assessment extends beyond the simple availability of more bands to work with. Typically, these bands record reflectance from much narrower regions of the electromagnetic spectrum. This narrowband design provides two key modeling capabilities that are not possible with broadband sensors: (1) narrow bands are able to target specific absorption features linked to specific physiological structures or processes that we can directly relate to plant stress response and (2) narrow, contiguous bands allow us to consider the overall shape of spectral signatures, including mathematical techniques (e.g., derivatives, area under the curve, slope of the line between key regions) that are not possible with broadband data.

Building off of the science of spectroscopy (the study of constituents and materials using specific wavelengths), RS analysts have used hyperspectral imagery to quantify specific vegetation constituents and processes. The best hyperspectral narrow bands to study vegetation are in the 400-2500 $\mathrm{nm}$ spectral range (Thenkabail et al. 2013; Fig. 6.8), enabling direct links to species composition, foliar chemistry, foliar function, and ecosystem characteristics (Smith et al. 2002; Williams and Hunt 2002; Kokaly et al. 2003; Asner and Heidebrecht 2003; Townsend et al. 2003; Carter et al. 2005; Cheng et al. 2006; Singh et al. 2015).

While it is generally believed that spectral changes in stressed vegetation are common across stress agents, the ability of hyperspectral sensors to target specific 
chemical, physiological, and morphological traits allows RS analysts to target and assess specific, early symptoms of decline and target detection efforts based on known physiological responses to a particular pest or pathogen. Lausch et al. (2013) targeted changes in chlorophyll absorption as an indicator of bark beetle-induced decline; Pontius et al. (2008) targeted chlorophyll fluoresce to map the invasive emerald ash borer (Pontius et al. 2008) and canopy density for detailed monitoring impacts of hemlock woolly adelgid (Pontius et al. 2005b).

Hyperspectral imagery has historically been limited in availability. NASA's Airborne Visible/Infrared Spectrometer (AVIRIS; Porter and Enmark 1987) hyperspectral sensor was the pioneer of airborne applications. But the launch of the NASA Hyperion Instrument (Pearlman et al. 2003) on the EO-1 satellite in 2000, and the addition of commercial vendors with aerial hyperspectral platforms (e.g., ITRES http://www.itres.com/; SPECIM http://www.specim.fi/hyperspectral-RS/), has increased the availability of hyperspectral imagery. The promise of new hyperspectral satellites such as the Environmental Mapping and Analysis Program (EnMAP http://www.enmap.org/mission.html) suggests there is potential for expanding applications in forest health monitoring and assessment. Recent examples include assessments of hemlock woolly adelgid-induced decline in the Catskills region of New York (Hanavan et al. 2015) and detection of drought-induced decline in the chaparral ecosystems of California (Coates et al. 2015). Fused hyperspectral and LiDAR imagery have also enabled the assessment of early decline at the canopy level in urban environments (e.g., Degerickx et al. 2018; Pontius et al. 2017).

\subsection{Spectroscopy of Early Decline Detection}

While different species have unique spectral signatures, there are similar changes in general spectral characteristics in response to stress (Buschmann and Nagel 1993). Many of these spectral features can be directly linked to the stress symptoms and physiological characteristics described above (Fig. 6.8). For example, changes in leaf chemistry and physiology are captured in the 480-520 $\mathrm{nm}$ (blue) and 600-680 nm (red) regions, where chlorophyll absorption is strong. But changes in this region are relatively small compared with the dramatic changes that can be seen with stress between 750 and $1300 \mathrm{~nm}$. The sharp rise in reflectance between the red and NIR regions (red edge inflection point) can be used to quantify changes in both the slope of the spectral signature and the location of the inflection point of the slope in response to changes in leaf chemistry and canopy density. Spectral information at longer wavelengths (1650-2200 shortwave infrared) has also been useful in quantifying changes in leaf water content, often a key signal of early vegetation stress.

Often the most useful information about general canopy condition, density, and function is derived from combining bands from various regions in mathematical expressions referred to as vegetation indices (Elvidge and Chen 1995; Pinty et al. 1993). Sometimes these indices incorporate information from multiple wavelengths with known absorption features. But other times a nonresponsive "control" band 


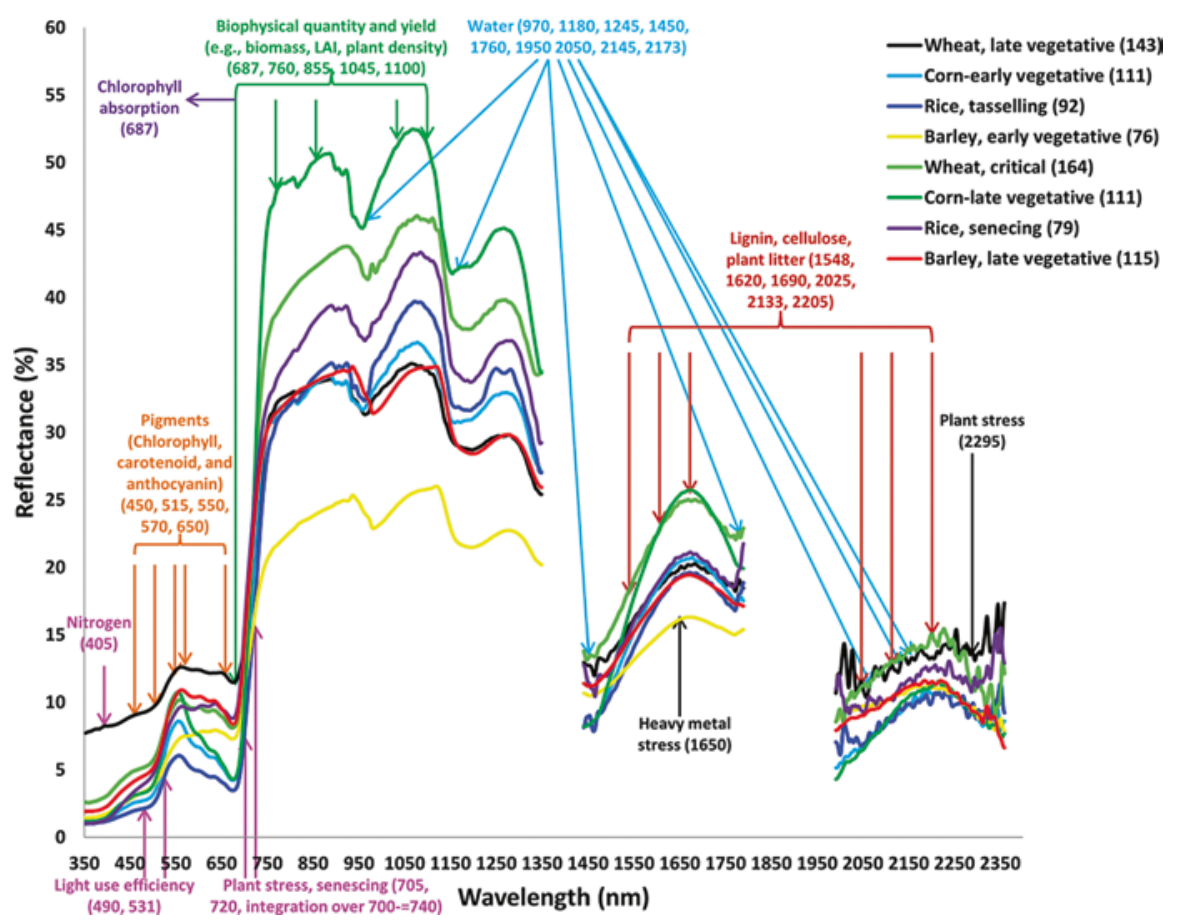

Fig. 6.8 Hyperspectral RS of vegetation condition is possible because of a suite of absorption and reflectance features across the visible and NIR spectra. (Credit: USGS by P. Thenkabail)

may be used to help account for differences in reflectance due to illumination or topography. Many vegetation indices have been designed for use with specific broadband sensors to assess general canopy characteristics such as relative "greenness," canopy density, or canopy condition (Table 6.1). But because of contributions in the field of spectroscopy, there is a wealth of literature that highlights specific regions of the electromagnetic spectrum (EMS) that are specifically associated with foliar chemistry, chlorophyll or carotenoid content, various metrics of photosynthetic activity, and other common stress markers (see Serbin et al. 2014, 2015; Singh et al. 2015).

Some of the vegetation indices listed in Table 6.1 are easily captured with widely available sensors. Others require reflectance information from narrow spectral regions that may only be accurately measured with hyperspectral sensors. Others may be located in regions that are outside of the EMS range of the imagery that is available. Thus, the number of available indices will depend on the imagery you have. Which index will prove most useful in detecting early canopy stress depends on the specific stress symptoms and the conditions of your study area. For example, in ecosystems with relatively sparse vegetation, a soil-adjusted vegetation index may work best to minimize the impact of background reflectance. Similarly, in ecosystems with very dense vegetation, you may need to select an index that does not saturate at high bio- 
mass levels. In most cases, you won't know which index, or set of indices and wavelengths, is best to use until you examine them as a part of your analyses. The best way to identify useful vegetation indices is detailed in the next section.

\subsection{Techniques for Early Stress Detection}

While mapping severe or widespread forest decline can be relatively straightforward using simple vegetation indices, it can be much more challenging to identify early or small-scale decline, particularly in mixed forests. For example, an insect outbreak may cause severe decline symptoms in the host tree species, but this signal may be washed out in a heterogeneous forest where reflectance from the larger canopy of other species dominates. Similarly, tree mortality is often accompanied by the release and ingrowth of understory vegetation. This can make detection of decline difficult as increased vegetation density from the understory masks the reduction in vegetation density in the upper canopy. Further, different species inherently have different chemical and structural characteristics, resulting in sometimes starkly different spectral signatures, even among healthy canopies. A healthy oak may be spectrally similar to a declining sugar maple. This underscores the importance of knowing the distribution of species across a landscape of interest and the characteristics of a "healthy" vs. "declining" spectral signature for a target forest type.

Because the identification of subtle stress characteristics relies on subtle changes in spectral characteristics, RS of early decline is very sensitive to anything that might alter spectral signatures. For example, an algorithm designed for early stress detection with one instrument may not be appropriate to apply to imagery from a different sensor. Even with a similar spectral, radiometric, and spatial configuration, differences in calibration may introduce differences that have nothing to do with the health of the canopy. Even when using the same instrument, atmospheric or illumination conditions may vary over time. For these reasons, it is important to calibrate each image to the specific conditions (atmospheric, illumination, canopy condition) at the time of acquisition.

There are several methodological approaches that can help to isolate and quantify decline symptoms, regardless of the sensor system (Pontius and Hallett 2014). Here we summarize the key components to identifying and quantifying early vegetation stress:

1. Know the spectral characteristics of your baseline ecosystem. While all vegetation has a common spectral curve, there are distinct differences in the spectral signature across different species and at different spatial resolutions. Because of inherent differences in foliar chemistry and canopy structure, a sugar maple has a spectral signature that is distinct from an eastern hemlock, even when both are in optimal health. Because of the spectral contribution from surrounding surface features, a healthy sugar maple in a heterogeneous forest will look different from 
a healthy sugar maple grown in someone's front yard. Thus, it is important to know what the spectral signature for a pixel of your target ecosystem would look like in optimal condition.

There are many spectral libraries where "typical" spectra for a range of surface features can be downloaded and used for image calibration (e.g., ECOSTRESS Spectral Library https://speclib.jpl.nasa.gov/documents/jhu_desc or US Geological Survey (USGS) Spectral Library https://crustal.usgs.gov/speclab/QueryAll07a.php?quick_filter=vegetation). However, because of inherent differences between sensors, as well as atmospheric and illumination conditions at the time of image acquisition, it is best to also collect field spectra or identify homogeneous calibration pixels from across the imagery. Linking field data directly to the pixels will provide a spectral signature that is specific to the imagery you are using and ecosystem you are working in. This will serve as an important baseline and provide essential calibration data to model the species and stress condition of interest.

2. Identify, quantify, and gather calibration data for the specific stress symptoms you expect to see. While there are many common stress responses across vegetation types and stress agents, many symptoms can be species- or stress-specific. Of these, only some may be visible to the human eye. This is why it is important to identify the common stress symptoms you expect to see, from the earliest symptoms to the most obvious and severe decline, and design field data collection efforts that quantify each of those stress symptoms. Field calibration data should include measurements from locations across the imagery and cover the full range for each of these metrics that you would expect to manifest in the system you are studying and that you hope to quantify in your final product. These field data will provide valuable information as you analyze your imagery and model decline conditions across your study area.

For example, hemlock woolly adelgid feed on photosynthate stored within hemlock twigs, limiting the ability of trees to put on new growth. This may not be visible in a broad assessment of canopy vigor, but can be quantified in the field by collecting multiple branches from across the canopy and assessing the proportion of terminal branchlets that have put on new growth. This serves as a relatively quick and low-tech way to quantify foliar productivity and the reductions in new growth that are often the first sign of infestation. Similarly, the most obvious visible sign of emerald ash borer infestation in ash trees is often scarified bark that results from increased woodpecker activity. Woodpeckers strip bark as they feed on larvae, leaving obvious white markings. These telltale signs of early infestation can serve as a proxy for subtle biophysical changes in the canopy that are not yet visible to field crews.

Most often, decline manifests as many different concurrent stress symptoms (e.g., chlorosis and defoliation and dieback in various parts of the canopy) or a progression of decline symptoms that vary with the degree of impact (e.g., early decline manifests as chlorosis, later stages dominated by reductions in the live crown ratio, and ultimately mortality). In such cases, you may choose to develop an aggregate "field health" index that mathematically normalizes a suite of stress 
metrics into one summary metric (Pontius and Hallett 2014). This may be easier and more efficient than creating models to assess each of the various decline symptoms you expect to see in your target system or having to pick one decline metric to use.

3. Calibrate imagery with field data. In an ideal world, we would be able to develop one model that could be automated and applied to imagery over time and space regardless of sensor, acquisition condition, or location. Several automated RS tools currently available (see Sect. 6) have proven incredibly useful for monitoring large areas over time. But automated applications are limited in their ability to detect subtle, early decline, which requires careful calibration between the imagery acquired and ground conditions at the time that imagery was collected to make it possible to identify the targeted stress response while controlling for other sources of spectral variability. Ideally, field calibration data can be collected within several weeks of imagery acquisition (or at least before conditions on the ground change). GPS locations of field calibration sites link field data to the spectra of the associated pixel or pixels to calibrate the larger image.

Various proprietary software modules exist for spectral calibration, modeling, and analyses. These modules can range from simple classification techniques that match pixels to various stages of decline based on your calibration spectra, to more complex spectral unmixing algorithms that approximate the proportion of "healthy to declining" spectra contained within each pixel. Even without specialized RS software, simple statistics can be used to quantify relationships between spectral reflectance and derived vegetation indices using field calibration data. A common approach is to use correlations between individual vegetation indices and decline metrics to qualitatively assess canopy condition across the landscape. Another approach uses multivariate statistical models to identify the best combination of bands or vegetation indices to quantify the decline metric of interest. Regardless of the mathematical approach, accuracy and detail are ultimately determined by the quality and range field calibration data available for model development. This type of targeted calibration to match the timing, location, and sensor characteristics for each decline assessment maximizes accuracy and detail of the final products.

4. Validate and assess accuracy to inform interpretation. One of the dangers inherent in linking RS products with management applications is overconfidence in the RS products. There is error inherent in each component of the RS process, from incorrect sensor calibration, to the variability introduced by atmospheric, topographic, and georegistration errors. However, when presented with a RS product, many end users develop their plans without consideration of how accurate the product may be or how inaccuracies can be avoided.

Any RS product should include some measure of accuracy as well as any caveats that should be considered in its use. In some cases (e.g., the use of a vegetation index to qualitatively describe relative states of decline), it is sufficient to remind users that the scale presented is intended to be relative and does not necessarily identify stands in specific states of decline or resulting from specific stress agents. In other cases (e.g., the classification of pixels into levels 
of decline), we can use field data to present an accuracy assessment. Any accuracy assessment of classified image products should include overall accuracy as well as users' accuracy (percent of target pixels correctly classified; inverse $=$ errors of omission) and producers' accuracy (percent of nontarget pixels that are not classified as the target class; inverse = errors of commission; Congalton 2001; Fassnacht et al. 2006). Splitting accuracy into users' and producers' values allows the end user to understand how false positives (saying a stand is dead when it is not) and false negatives (saying a stand is healthy when it is dead) can influence how the end product is used to inform management activities. For example, if overall accuracy in classifying forest mortality is $70 \%$ but almost all of the error results from false positives (many stands classified as dead when they are actually alive), end users may decide to limit management to locations with large clusters of predicted mortality or to clusters in higherdecline categories in order to avoid these common errors.

RS decline-detection products that result in ordinal classes of decline (e.g., healthy, degrees of decline, dead) can also be assessed for "fuzzy accuracy," which considers not only correct class assignments but also those within one ordinal class of the correct class. Products that provide a continuous decline metric can be used to produce more detailed accuracy metrics. Standard statistical regression techniques produce a coefficient of determination $\left(r^{2}\right)$ to describe how well a statistical model fits the relationship between the input spectral variables and the output decline metric. Root mean square error, standard errors, and prediction errors can be used to place confidence bounds on predicted values. We can also examine how accuracy changes across the range of decline values predicted. For example, some models may be very good at quantifying severe decline but may not be able to detect early decline symptoms. Some models may overpredict early decline but underpredict severe decline. Standard statistical methods can be useful to examine how well your model works, which is critical to ensure that end users know how to best integrate your resulting RS products into their decision-making process.

A Nested Approach No one sensor, field methodology, or scale is appropriate for all applications. Different goals may require that you work at different scales (Fig. 6.9). The most detailed and accurate information about specific stress agents and response symptoms will always be obtained from on-the-ground field surveys (Tier 1). Such location-specific studies allow researchers to directly measure foliar chemistry, canopy structure, and spectral characteristics in situ. But these studies are limited in their utility to inform management across the broader landscape. Aerial sensors are often used to collect RS imagery at the local scale (Tier 2). Typically, this scale allows for the use of high spatial and spectral resolution imagery, ideally suited to detect forest stress conditions. However, such efforts may still be limited in geographic extent due to the high cost and computing needs. Most common is the use of broadband sensors at the regional-continental scale (Tier 3). Landsat sensors have been widely used for such applications, with sufficient spatial $(30 \mathrm{~m})$ and spectral resolution to prove useful in assessment of 
Fig. 6.9 RS work occurs at a variety of scales, with benefits and limitations at each level. Sometimes the best approach includes nesting your analyses across multiple scales to gain a comprehensive understanding of the forest health dynamics on the ground

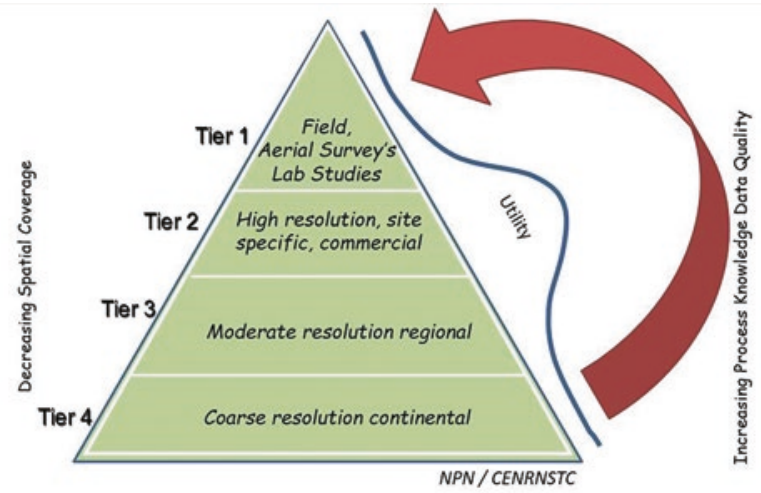

relative levels of forest decline. The recent addition of improved satellite sensors (e.g., Sentinel 2) is rapidly increasing the capability to cover broad landscapes at higher spatial resolutions. Global assessments (Tier 4) of forest condition typically require a reduction in spatial resolution in order to process information over vast geographic extents. The much larger, mixed pixels often mask subtle changes in vegetation condition but can be useful in time series analyses when focused on relative changes in vegetation indices on continental scales.

The best approach to mapping and modeling forest decline depends on the scale of the investigation, level of detail needed, resources available, and time frame. For example, a regional assessment may have to forgo spatial and spectral resolution (and predictive detail and accuracy) in order to achieve the spatial coverage desired. In contrast, a municipality concerned about the spread of a recently detected invasive insect pest may forgo widespread spatial coverage to maximize the spatial and spectral resolution necessary to identify individual, newly infested trees. Sometimes you are limited by what is available in terms of imagery, time, or financial resources. For example, it is impossible to go back in time to collect high-resolution imagery, but you may be able to make use of historical broadband satellite imagery for a general assessment of past conditions. In most cases RS products, even when not exactly matched to the user's needs, can still provide insight that is not available through traditional monitoring.

Perhaps the most comprehensive approach to detecting novel forest health issues is to combine approaches. For example, a broad landscape assessment can be useful to identify localized areas for more detailed image acquisition. Even better, examining the relationship between spectral characteristics from higher-resolution imagery could be used to train coarser resolution imagery for a larger-scale assessment. The key is to recognize that there is no one right approach and that perhaps there are several RS approaches that can be used to achieve your objectives.

Stakeholder Engagement For each of the steps suggested above, stakeholder engagement is critical to success. RS specialists typically are not experts in entomology, invasive species, tree physiology, or forest ecology, and may not be aware 
of the specific stress symptoms to target for a given application. Because we work in various locations, we are rarely experts on the ecological specifics of a new study area. Where can we find target species or stands in various stages of decline? What key landscape features or characteristics should be covered in our calibration to best inform management? We also may not be sure how the products we develop could be most useful to land managers and practitioners. Would a classification product be most useful, with simple "healthy vs. dead" groupings, or would a range of decline condition be better? Do we need to develop a species map first to better target the declining stands end users hope to find? Are they looking for potential healthy "refugia" areas for conservation, newly declining stands for intervention, or highmortality stands for salvage? Knowing what they need will allow us to design our modeling outputs to best suit their needs.

To maximize the impact of the products you develop, we suggest engaging a range of stakeholders throughout the entire process, for example:

- Go beyond simply obtaining letters of support to include end users and other key stakeholders in proposal development and experimental design from the outset of a new project.

- Find practitioners in your study area to identify and visit potential field sites.

- Present at local and regional meetings with the specific intent to introduce the project and solicit feedback on product format and delivery (prior to obtaining results).

- Include stakeholders in fieldwork, training them in field methodologies and learning from their expertise. Creating a sense of ownership or investment in a project improves the chances that your final products will actually be used.

- Meet with potential users as products are developed to gauge if the format (metric scale/range, spatial resolution, file format, etc.) are useful and, if not, how you might modify products to meet their needs.

- In addition to presenting your results at scientific meetings, target professional meetings and workshops to reach end users.

- Make your data products easily discoverable and available. This may include posting final products in online databases or web portals. Be sure the format is not limiting. Google Earth provides a useful platform for users without ARC or other proprietary geocomputing resources.

Including stakeholders in this way not only helps maximize the utility and impact of your efforts but also builds bridges between scientific and management communities. Historically, there have been limited collaborations among land managers, practitioners, decision-makers, and the RS scientific community. In some cases, there has even been mistrust as products are promised but delivered on a scientific timeline rather than a management timeline. But there has been a recent push to include stakeholders in RS and modeling efforts, exemplified by the recent "Voices from the Land" project led by researchers at Harvard Forest (McBride et al. 2017). This stakeholder-driven approach used interviews with New Englanders to identify key outcomes and likely scenarios for modeling. Such steps can build relationships that can serve all communities interested in sustaining forested ecosystems. 


\subsection{Using RS to Inform Forest Management}

The application of RS for vegetation stress detection has advanced rapidly, evolving from classical aerial survey and photointerpretation techniques to digital image processing, where manual interpretation has been replaced with machine learning to identify subtle signatures humans are incapable of seeing with the naked eye. This technological evolution has effectively transferred these tools to the sustainable management of forest resources, but limitations remain in their widespread use. Monitoring, detecting, and reporting on forest health threats has always been a priority of federal and state forestry agencies. Conversion of forest land and changes in land use; climate change, intensified storms, higher frequency and intensity of forest fires and concerns of host range recession; and the threat of introduction and establishment from invasive insects and diseases have created an even more urgent demand for improved near-real-time tools and products. The capabilities of most sensors and the applications on which they have been tested are impressive, and more promising techniques and approaches continue to build on field application.

Recently, several programs have been developed with the goal of advancing and improving RS applications for forest management, including online tools developed to bring RS products to the forest health management community in near real time. Here we present some examples of online resources developed to transfer RS products to end users on time scales useful to inform management and planning.

World Vegetation Health Index https://www.star.nesdis.noaa.gov/smcd/emb/vci/ VH/vh_browse.php The National Oceanic and Atmospheric Administration (NOAA)-National Environmental Satellite, Data, and Information Service (NESDIS) has developed several RS products designed specifically to assess vegetation health across the globe. Their Center for Satellite Applications and Research (STAR) Vegetation Health Index (Fig. 6.10) uses Advanced Very High-Resolution Radiometer (AVHRR) imagery produced from the NOAA/NESDIS Global Area Coverage (GAC) data set from 1981 to the present, with $4 \mathrm{~km}$ spatial and 7-day composite temporal resolution. Common vegetation indices are used to estimate vegetation health, moisture, and temperature and serve as a proxy to monitor vegetation cover, density, productivity, and drought conditions, as well as phenological stages such as the start/end of the growing season. Outputs are scaled to a range $(0$ to 100), providing a relative assessment of vegetation condition rather than a prediction of actual decline symptoms or identification of stress agents. However, these products are useful for examining short-term changes in vegetation that can be used to identify widespread decline events such as drought, land degradation, or fire.

ForWarn Online Mapper http://forwarn.forestthreats.org/; https://forwarn.forestthreats.org/fcav2/ ForWarn Satellite-Based Change Recognition and Tracking (Fig. 6.11) is a near-real-time product from the US Forest Service that uses $250 \mathrm{~m}$ MODIS data to compare current NDVI to seasonally similar historic NDVI values to identify disturbance such as wildfires, windstorms, insects, disease outbreaks, 


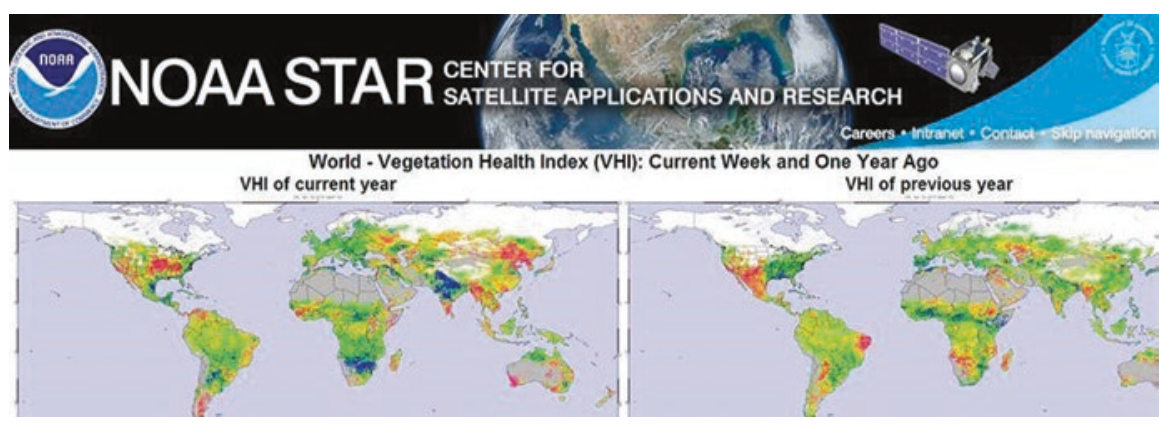

Fig. 6.10 The NOAA STAR World Vegetation Health Index visualization and data download portal

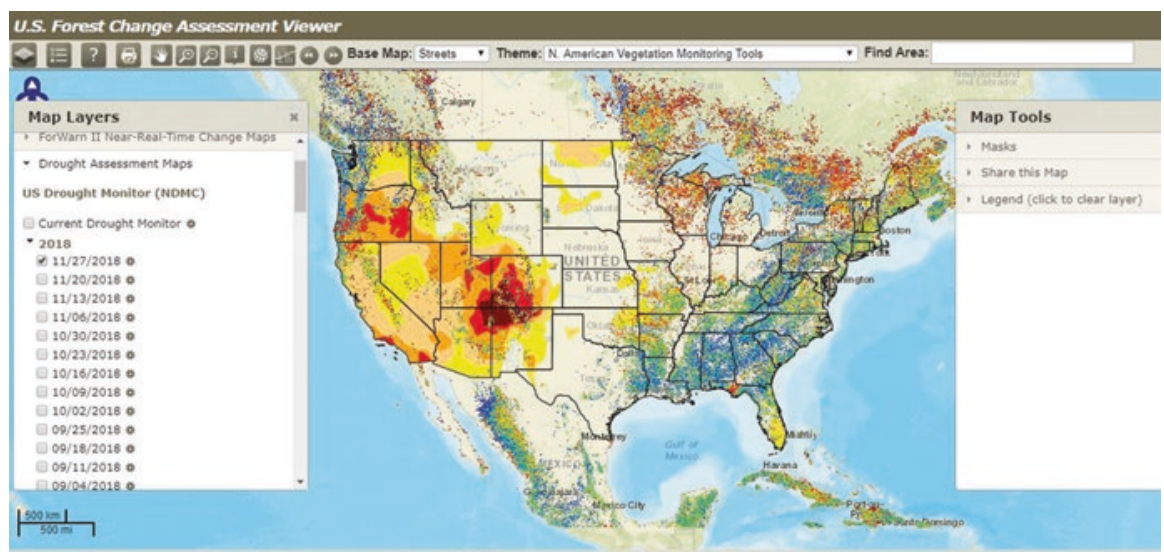

Fig. 6.11 The USFS ForWarn II online mapping portal provides weekly vegetation change and identification products dating back to 2003

logging, and land use change (Norman et al. 2013). Recent improvements in historical NDVI baseline data now provide the end user more tools to diagnose the severity and cause of changes in the mapping products.

\section{Forest Disturbance Monitor (FDM) and Operational Remote Sensing} (ORS) https://foresthealth.fs.usda.gov/FDM; http://foresthealth.fs.usda.gov/portal The US Forest Service Forest Disturbance Monitor (FDM; Fig. 6.12) is a forest disturbance web portal based on 16-day and 24-day MODIS composites that are updated every 8 days. FDM produces two forest disturbance products, 3-year RealTime Forest Disturbance (RTFD) data and 5-year Trend Disturbance Data (TDD), providing near-real-time forest disturbance maps for land managers to target forest insect and disease events and complement aerial sketch mapping annual insect and disease surveys (IDSs; Chastain et al. 2015). 


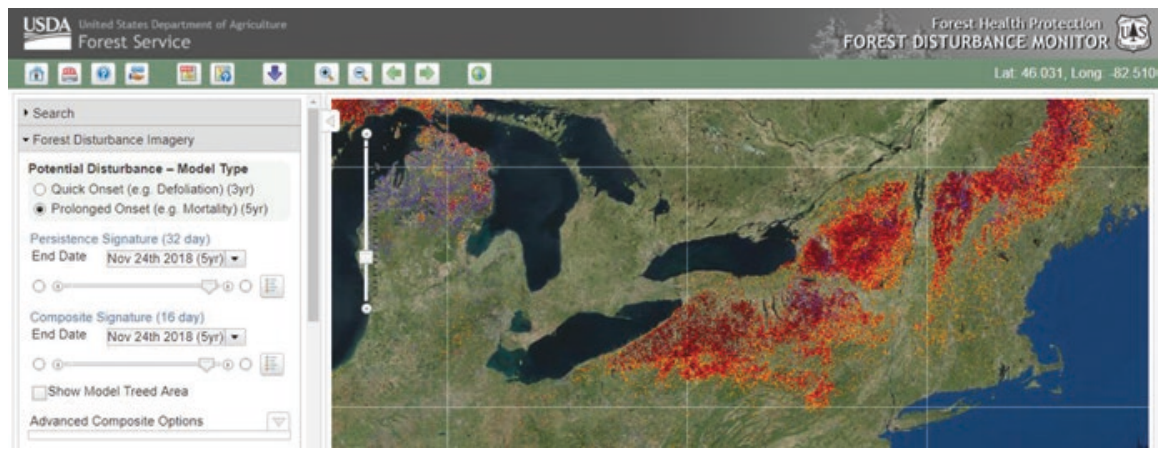

Fig. 6.12 The USFS Forest Disturbance Monitor online portal

To improve insect and disease surveys and facilitate the use of forest health information that RS products can provide, the USFS has recently initiated the Operational Remote Sensing (ORS) program. Similar to the FDM, ORS will use a phenologybased approach to intensifying surveys using $30 \mathrm{~m}$ Landsat and other moderateresolution data.

Ecosystem Disturbance and Recovery Tracker (eDaRT) http://www.cstarsd3s. ucdavis.edu/systems/edart/ A collaboration among the University of California, Davis, Center for Southeastern Tropical Advanced Remote Sensing (CSTARS), and the US Forest Service, the Ecosystem Disturbance and Recovery Tracker (eDaRT; Koltunov et al. 2015) is an automated system that provides a suite of Landsatderived products to identify and categorize changes in forest, shrubland, and herbaceous ecosystems. Currently, eDaRT products are not publicly available, but recent efforts are focused on expanding operations by the US Forest Service in California and elsewhere in the western United States in support of daily ecosystem management tasks.

Looking Ahead Because of the vast potential for RS to inform the sustainable management of terrestrial landscapes, there are several new Earth observation missions on the horizon. The European Space Agency (ESA) will launch Earth Explorer 7 in 2021 (https://www.esa.int/Our_Activities/Observing_the_Earth). This ecology mission, known as Biomass, is designed to characterize forests. The Biomass mission will be followed by the Earth Explorer 8 Fluorescence Explorer (FLEX) mission in 2022, with capabilities to quantify chlorophyll fluorescence in terrestrial vegetation. Landsat 9, part of the Earth observation data continuity mission from NASA (fast-tracked for December 2020 launch date), will maintain nearly 50 years of continuous Earth observation. This instrument is designed to simultaneously image 11 spectral bands, including a $15 \mathrm{~m}$ panchromatic band, with 12 bit radiometric resolution to increase sensitivity to small differences in reflectance. Such advances are critical to the early stress detection and detailed decline assessment that land managers need. 


\subsection{Management Applications: Limitations and Opportunities}

Thanks to continuing advances in computing and software technologies, we are poised to bring near-real-time RS products to more stakeholders. Applications like Google Earth Engine (https://earthengine.google.com/) now have the ability to automate image acquisition, preprocessing, and more complex modeling algorithms to provide critical forest health information across large landscapes at regular time intervals. Similarly, the ESA's Grid Processing on Demand (G-POD) provides an online environment where scientists can build and automate RS applications (https:// gpod.eo.esa.int/). While several organizations (see ForWarn, FDM, and eDaRT above) are making final products from this type of rapid analysis and assessment operational for coarse forest health assessments and disturbance mapping efforts, higher-level products (higher spatial resolution, low-level stress detection) are not yet publicly available for use by broad stakeholder groups.

Currently, most RS efforts to detect incipient stress factors or detailed vegetation condition are conducted by the research community with scientific journals as their primary outputs. The more widespread use of more advanced RS techniques in forest management is primarily limited by:

- The cost of image acquisition and expertise required to accurately calibrate sensors and validate products. This is particularly true for hyperspectral efforts, which generate large amounts of data and require specialized expertise for preprocessing corrections, calibration, and data management. Computing advances and the growing commercial sector promise improved access, but for many land managers, cost is still a strong deterrent. Some organizations are hoping to make cutting-edge imagery more accessible. For example, NASA's Goddard's LiDAR, Hyperspectral, and Thermal Imager (G-LiHT) (https://gliht.gsfc.nasa.gov/) is a portable, airborne imaging system that simultaneously maps composition, structure, and function of terrestrial ecosystems using multispectral LiDARs (3-D information about the vertical and horizontal distribution of foliage and other canopy elements), hyperspectral imaging spectrometer to discern species composition and variations in biophysical variables (photosynthetic pigments and nutrient and water content), and a thermal camera to measure surface temperatures to detect heat and moisture stress (Cook et al. 2013). Owned and operated by NASA Goddard, this instrument has proven to be more affordable and accessible than comparable commercial vendors and may greatly expand access to cutting-edge sensor technologies for a variety of applications (Fig. 6.13).

- The turnaround time required to deliver final mapping products. Typically, the more irruptive forest health issues require immediate attention in the current growing season (e.g., pest outbreaks, extreme climate events, wildfires), while turnaround from RS projects doesn't always occur in the same year. This disparity between product delivery and product need is especially evident in studies 


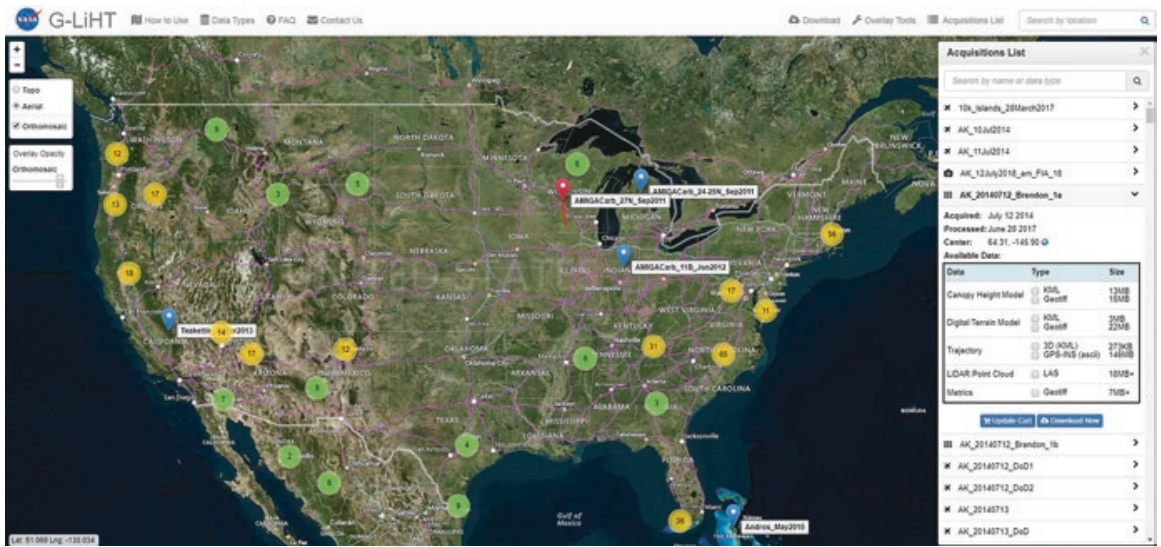

Fig. 6.13 NASA's G-LiHT online data portal

where method development is necessary and limits the adoption of more advanced RS efforts by the forest management community. However, the increased use of automated image processing scripts that make satellite image products available in near real time is expanding the use of traditional (vegetation index-based) relative assessments available for a variety of applications. The resulting online tools described above are being adopted by a range of state and federal agencies to inform management decisions.

- Integration of mapping products into decision-making processes. Even when RS products are available, there is no clear path on how to use the information they provide to inform decision-making. Land managers may reference mapping products to target specific locations, but more complete integration of spatial products into management plans can be challenging for those not used to working with spatial data. Foresters are typically trained in making decisions based on generalized inventories of forest stands or management units, not pixelated rasters across a landscape with a high degree of variability. End users may not be aware that mapping products should come with an accuracy assessment that informs how the information can best be used and how it impacts the overall confidence in the product. Many of these limitations can be resolved by scientists working more closely with end users as outlined in the Stakeholder Engagement section above. By working together, both scientists and land managers can learn from each other and so better use RS technologies to manage critical environmental resources. 


\subsection{Conclusions}

While historically RS has been successfully used to assess and monitor vegetation condition on a coarse, relative scale, recent advances and new analysis techniques now enable us to also use RS to identify and track early decline, disturbance, and stress conditions in vegetative systems. Considering the environmental challenges currently facing terrestrial systems, this information is critical to inform management, policy, and planning in order to maintain the structure and function of these systems.

The challenge is for scientists to look beyond traditional approaches to vegetation assessment and target earlier or more subtle decline response resulting from incipient or chronic environmental stress agents (e.g., climate change, pollution). Key challenges include linking hyperspectral data to specific stress agents, extending the availability of higher-resolution imagery, and operationalizing near-realtime monitoring of the forest resource (Senf et al. 2017). Scientists must work closely with land managers to bring these new technologies to application in order to harness RS's full potential to inform the management of critical ecological resources.

\section{References}

Aoki M, Yabuki K, Totsuka T (1981) An evaluation of chlorophyll content of leaves based on the spectral reflectivity in several plants. Res Rep Nat Inst Environ Stud Jpn 66:125-130

Asner GP, Heidebrecht KB (2003) Imaging spectroscopy for desertification studies: comparing AVIRIS and EO-1 Hyperion in Argentina drylands. IEEE Trans Geosci Remote Sens 41(6): 1283-1296

Barnes JD (1992) A reappraisal of the use of DMSO for the extraction and determination of chlorophylls a and b in lichens and higher plants. Environ Experim Bot 32(2):85-100

Blackburn GA (1998) Quantifying chlorophylls and carotenoids at leaf and canopy scales: an evaluation of some hyperspectral approaches. Remote Sens Environ 66(3):273-285

Blackburn GA (1999) Relationships between spectral reflectance and pigment concentrations in stacks of deciduous broadleaves. Remote Sens Environ 70:224-237

Boochs F, Kupfer G, Dockter K, Kuhbauh W (1990) Shape of the red edge as vitality indicator for plants. International Journal of Remote Sensing 11(10):1741-1753

Broge NH, Leblanc E (2001) Comparing prediction power and stability of broadband and hyperspectral vegetation indices for estimation of green leaf area index and canopy chlorophyll density. Remote Sens Environ 76(2):156-172

Buschmann C, Nagel E (1993) In vivo spectroscopy and internal optics of leaves as a basis for remote sensing of vegetation. Int J Remote Sens 14:711-722

Carter GA (1993) Responses of leaf spectral reflectance to plant stress. Am J Bot 80(3):239-243

Carter GA (1994) Ratios of leaf reflectances in narrow wavebands as indicators of plant stress. Int J Remote Sens 15(3):697-703

Carter GA, Knapp AK (2001) Leaf optical properties in higher plants: linking spectral characteristics to stress and chlorophyll concentration. Am J Bot 88(4):677-684

Carter GA, Miller RL (1994) Early detection of plant stress by digital imaging within narrow stress-sensitive wavebands. Remote Sens Environ 50(3):295-302 
Carter GA, Knapp AK, Anderson JE, Hoch GA, Smith MD (2005) Indicators of plant species richness in AVIRIS spectra of a mesic grassland. Remote Sens Environ 98:304-316

Chappelle EW, Kim MS, McMurtrey JE III (1992) Ratio analysis of reflectance spectra (RARS): an algorithm for the remote estimation of the concentrations of chlorophyll a, chlorophyll b, and carotenoids in soybean leaves. Remote Sens Environ 39(3):239-247

Chastain RA, Fisk H, Ellenwood JR, Sapio FJ, Ruefenacht B, Finco MV, Thomas V (2015) Nearreal time delivery of MODIS-based information on forest disturbances. In: Time-sensitive remote sensing. Springer, New York, pp 147-164

Chen J (1996) Evaluation of vegetation indices and a modified simple ratio for boreal applications. Can J Remote Sens 22(3):229-242

Cheng Y-B, Zarco-Tejada PJ, Riano D, Rueda CA, Ustin SL (2006) Estimating vegetation water content with hyperspectral data for different canopy scenarios: relationships between AVIRIS and MODIS indexes. Remote Sens Environ 105(2006):354-366

Coates AR, Dennison PE, Roberts DA, Roth KL (2015) Monitoring the impacts of severe drought on southern California chaparral species using hyperspectral and thermal infrared imagery. Remote Sens 7(11):14276-14291

Congalton RG (2001) Accuracy assessment and validation of remotely sensed and other spatial information. Int J Wildland Fire 10(3-4):321-328

Cook BD, Corp LW, Nelson RF, Middleton EM, Morton DC, McCorkel JT, Masek JG, Ranson KJ, Ly V, Montesano PM (2013) NASA Goddard's Lidar, Hyperspectral and Thermal (G-LiHT) airborne imager. Remote Sens Environ 5:4045-4066

D'ambrosio N, Szabo K, Lichtenthaler H (1992) Increase of the chlorophyll fluorescence ratio F690/F735 during the autumnal chlorophyll breakdown. Radiat Environ Biophys 31(1):51-62

Datt B (1998) Remote sensing of chlorophyll a, chlorophyll b, chlorophyll a + b, and total carotenoid content in eucalyptus leaves. Remote Sens Environ 66:111-121

Datt B (1999) Visible/near infrared reflectance and chlorophyll content in Eucalyptus leaves. Int J Remote Sens 20(14):2741-2759

Daughtry CST, Walthall CL, Kim MS, de Colstoun EB, McMurtrey JE (2000) Estimating corn leaf chlorophyll concentration from leaf and canopy reflectance. Remote Sens Environ 74(2):229-239. https://doi.org/10.1016/s0034-4257(00)00113-9

Deblonde G, Cihlar J (1993) A multiyear analysis of the relationship between surface environmental variables and NDVI over the Canadian landmass. Remote Sens Rev 7:151-177

Degerickx J, Roberts DA, McFadden JP, Hermy M, Somers B (2018) Urban tree health assessment using airborne hyperspectral and LiDAR imagery. Int J Appl Earth Obs Geoinf 73:26-38

Ellison AM, Barker-Plotkin AA, Foster DR, Orwig DA (2010) Experimentally testing the role of foundation species in forests: the Harvard Forest Hemlock Removal Experiment. Methods Ecol Evol 1(2):168-179. https://doi.org/10.1111/j.2041-210X.2010.00025.x

Elvidge CD, Chen Z (1995) Comparison of broad-band and narrow-band red and near-infrared vegetation indices. Remote Sens Environ 54(1):38-48

Elvidge CD, Lyon RJ (1985) Estimation of the vegetation contribution to the $165 / 222 \mu \mathrm{m}$ ratio in airborne thematic-mapper imagery of the Virginia Range, Nevada. Int J Remote Sens 6(1):75-88

Epanchin-Niell RS, Hastings A (2010) Controlling established invaders: integrating economics and spread dynamics to determine optimal management. Ecol Lett 13(4):528-541

Fassnacht KS, Cohen WB, Spies TA (2006) Key issues in making and using satellite-based maps in ecology: a primer. For Ecol Manag 222:167-181

Filella I, Penuelas J (1994) The red edge position and shape as indicators of plant chlorophyll content, biomass, and hydric status. Int J Remote Sens 15(7):1459-1470

Gamon JA, Serrano L, Surfus JS (1997) The photochemical reflectance index: an optical indicator of photosynthetic radiation use efficiency across species, functional types, and nutrient levels. Oecologia 112(4):492-501 
Gao BC (1996) Ndwi - a normalized difference water index for remote sensing of vegetation liquid water from space. Remote Sens Environ 58(3):257-266

Genovesi P, Carboneras C, Vila M, Walton P (2015) EU adopts innovative legislation on invasive species: a step towards a global response to biological invasions? Biol Invasions 17(5):1307-1311

Gitelson A, Merzlyak MN (1994) Quantitative estimation of chlorophyll-a using reflectance spectra: experiments with autumn chestnut and maple leaves. J Photochem Photobiol B Biol 22(3):247-252

Gitelson AA, Merzlyak MN (1996) Signature analysis of leaf reflectance spectra: algorithm development for remote sensing of chlorophyll. J Plant Physiol 148(3-4):494-500

Gitelson AA, Buschmann C, Lichtenthaler HK (1999) The chlorophyll fluorescence ratio F-735/F-700 as an accurate measure of the chlorophyll content in plants. Remote Sens Environ 69(3):296-302

Gitelson AA, Merzlyak MN, Chivkunova OB (2001) Optical properties and non-destructive estimation of anthocyanin content in plant leaves. Photochem Photobiol 74(1):38-45

Haboudane D, Miller JR, Pattey E, Zarco-Tejada PJ, Strachan IB (2004) Hyperspectral vegetation indices and novel algorithms for predicting green LAI of crop canopies: modeling and validation in the context of precision agriculture. Remote Sens Environ 90(3):337-352. https://doi. org/10.1016/j.rse.2003.12.013

Hanavan RP, Pontius J, Hallett R (2015) A 10-year assessment of hemlock decline in the Catskill Mountain region of New York State using hyperspectral remote sensing techniques. J Econ Entomol 108(1):339-349

Hardisky MA, Klemas V, Smart RM (1983) The influence of soil salinity, growth form, and leaf moisture on the spectral radiance of Spartina alterniflora canopies. Photogramm Eng Remote Sens 49(1):77-83

Harwood T, Tomlinson I, Potter C, Knight J (2011) Dutch elm disease revisited: past, present and future management in Great Britain. Plant Pathol 60(3):545-555

Hennon PE, D'Amore DV, Schaberg PG, Wittwer DT, Shanley CS (2012) Shifting climate, altered niche, and a dynamic conservation strategy for yellow-cedar in the North Pacific coastal rainforest. Bioscience 62(2):147-158

Horler D, DOCKRAY M, Barber J (1983) The red edge of plant leaf reflectance. Int J Remote Sens 4(2):273-288

Huete AR (1988) A soil adjusted vegetation index (SAVI). Remote Sens Environ 25(3):295-309. https://doi.org/10.1016/0034-4257(88)90106-x

Huete A, Justice C, Liu H (1994) Development of vegetation and soil indices for MODISEOS. Remote Sens Environ 49(3):224-234

Huete A, Didan K, Miura T, Rodriguez EP, Gao X, Ferreira LG (2002) Overview of the radiometric and biophysical performance of the MODIS vegetation indices. Remote Sensing of Environment 83(1-2): 195-213

Huggett BA, Schaberg PG, Hawley GJ, Eagar C (2007) Long-term calcium addition increases growth release, wound closure, and health of sugar maple (Acer saccharum) trees at the Hubbard Brook Experimental Forest. Can J For Res 37(9):1692-1700

Hunt ER, Rock BN (1989) Detection of changes in leaf water content using near infrared and middle infrared reflectances. Remote Sens Environ 30(1):43-54. https://doi. org/10.1016/0034-4257(89)90046-1

Johnson EW, Ross J (2008) Quantifying error in aerial survey data. Aust For 71(3):216-222

Johnson E, Wittwer D (2008) Aerial detection surveys in the United States. Aust For 71(3):212-215

Jordan CF (1969) Derivation of leaf area index from quality of light on the forest floor. Ecology (Washington DC) 50(4):663-666. https://doi.org/10.2307/1936256

Kaufman YJ, Tanre D (1992) Atmospherically resistant vegetation index (ARVI) for EOSMODIS. IEEE Trans Geosci Remote Sens 30(2):261-270

Kokaly RF, Despain DG, Clark RN, Livo KE (2003) Mapping vegetation in yellowstone national park using spectral feature analysis of AVIRIS data. Remote Sens Environ 84(3):437-456 
Kolb T, Teulon D (1991) Relationship between sugar maple budburst phenology and pear thrips damage. Can J For Res 21(7):1043-1048

Koltunov A, Ramirez C, Ustin SL (2015) eDaRT: the ecosystem disturbance and recovery tracking system prototype supporting ecosystem management in California. NASA Carbon Cycle and Ecosystems Joint Science Workshop College Park, MD, April, 19-24

Kosiba AM, Meigs GW, Duncan J, Pontius J, Keeton WS, Tait E (2018) Spatiotemporal patterns of forest damage in the Northeastern United States: 2000-2016. Forest Ecology and Management 430:94-104.

Lausch A, Heurich M, Gordalla D, Dobner HJ, Gwillym-Margianto S, Salbach C (2013) Forecasting potential bark beetle outbreaks based on spruce forest vitality using hyperspectral remote-sensing techniques at different scales. For Ecol Manag 308:76-89

Lausch A, Erasmi S, King D, Magdon P, Heurich M (2017) Understanding forest health with remote sensing-part II — a review of approaches and data models. Remote Sens 9(2):129

Lillesand TM, Kiefer RW (1994) Remote sensing and photo interpretation, 3rd edn. John Wiley\& Sons, New York

Maccioni A, Agati G, Mazzinghi P (2001) New vegetation indices for remote measurement of chlorophylls based on leaf directional reflectance spectra. J Photochem Photobiol 61(1,2):52-61

Martin K, Norris A, Drever M (2006) Effects of bark beetle outbreaks on avian biodiversity in the British Columbia interior: implications for critical habitat management. J Ecosyst Manag 7(3):10-24

McBride MF, Lambert KF, Huff ES, Theoharides KA, Field P, Thompson JR (2017) Increasing the effectiveness of participatory scenario development through codesign. Ecol Soc 22(3):16

McConnell TJ (1999) Aerial sketch mapping surveys, the past, present and future. In: Paper from the north American science symposium, toward a unified framework for inventorying and monitoring forest ecosystem resources, Guadalajara, Mexico

McMurtrey J III, Chappelle EW, Kim M, Meisinger J (1994) Distinguishing nitrogen fertilization levels in field corn (Zea mays L.) with actively induced fluorescence and passive reflectance measurements. Remote Sens Environ 47(1):36-44

Meroni M, Rossini M, Picchi V, Panigada C, Cogliati S, Nali C, Colombo R (2008) Assessing steady-state fluorescence and PRI from hyperspectral proximal sensing as early indicators of plant stress: the case of ozone exposure. Sensors 8(3):1740-1754. https://doi.org/10.3390/ s8031740

Merzlyak MN, Gitelson AA, Chivkunova OB, Rakitin VY (1999) Non-destructive optical detection of pigment changes during leaf senescence and fruit ripening. Physiol Plant 106(1):135141. https://doi.org/10.1034/j.1399-3054.1999.106119.x

Mohammed GH, Binder WD, Gillies SL (1995) Chlorophyll fluorescence - a review of its practical forestry applications and instrumentation. Scand J For Res 10(4):383-410

Mumford R (2017) New approaches for the early detection of tree health pests and pathogens. Impact 1(7):47-49

Myneni RB, Hall FG, Sellers PJ, Marshak AL (1995a) The interpretation of spectral vegetation indexes. IEEE Trans Geosci Remote Sens 33(2):481-486

Myneni RB, Maggion S, Iaquinta J, Privette JL, Gobron N, Pinty B, Kimes DS, Verstraete MM, Williams DL (1995b) Optical remote sensing of vegetation: modeling, caveats, and algorithms. Remote Sens Environ 51:169-188

Norman SP, Hargrove WW, Spruce JP, Christie WM, Schroeder SW (2013) Highlights of satellitebased forest change recognition and tracking using the ForWarn System. Gen Tech Rep SRSGTR-180 Asheville, NC: USDA-Forest Service, Southern Research Station, 30 p, 180:1-30

Pearlman JS, Barry PS, Segal CC, Shepanski J, Beiso D, Carman SL (2003) Hyperion, a spacebased imaging spectrometer. IEEE Trans Geosci Remote Sens 41:1160-1173

Pearson L, Miller LD (1972) Remote mapping of standing crop biomass for estimation of the productivity of the short-grass prairie, Pawnee National Grasslands, Colorado. In: Proceedings of the 8th international symposium on remote sensing of the environment, Ann Arbor, MI, 1972. ERIM, Ann Arbor, pp 1357-1381 
Penuelas J, Filella I, Biel C, Serrano L, Save R (1993) The reflectance at the 950-970 nm region as an indicator of plant water status. Int J Remote Sens 14(10):1887-1905

Penuelas J, Gamon JA, Fredeen AL, Merino J, Field CB (1994) Reflectance indices associated with physiological changes in nitrogen-limited and water-limited sunflower leaves. Remote Sens Environ 48(2):135-146. https://doi.org/10.1016/0034-4257(94)90136-8

Penuelas J, Baret F, Filella I (1995) Semi-empirical indices to assess carotenoids/chlorophyll a ratio from leaf spectral reflectance. Photosynthetica 31:221-230

Pietrzykowski E, Stone C, Pinkard E, Mohammed C (2006) Effects of Mycosphaerella leaf disease on the spectral reflectance properties of juvenile Eucalyptus globulus foliage. For Pathog 36(5):334-348

Pinty B, Leprieur C, Verstraete MM (1993) Towards a quantitative interpretation of vegetation indices. Part I. Biophysical canopy properties and classical indices. Remote Sens Rev 7:127-150

Pontius J (2014) A new approach for forest decline assessments: maximizing detail and accuracy with multispectral imagery. Int J Remote Sens 35(9):3384-3402. https://doi.org/10.1080/014 31161.2014 .903439

Pontius J, Hallett R (2014) Comprehensive methods for earlier detection and monitoring of forest decline. For Sci 60(6):1156-1163. https://doi.org/10.5849/forsci.13-121

Pontius J, Hallett R, Martin M (2005a) Assessing hemlock decline using visible and near-infrared spectroscopy: indices comparison and algorithm development. Appl Spectrosc 59(6):836-843. https://doi.org/10.1366/0003702054280595

Pontius J, Hallett R, Martin M (2005b) Using AVIRIS to assess hemlock abundance and early decline in the Catskills, New York. Remote Sens Environ 97(2):163-173. https://doi. org/10.1016/j.rse.2005.04.011

Pontius JA, Hallett RA, Jenkins JC (2006) Foliar chemistry linked to infestation and susceptibility to hemlock woolly adelgid (Homoptera: Adelgidae). Environ Entomol 35(1):112-120

Pontius J, Martin M, Plourde L, Hallett R (2008) Ash decline assessment in emerald ash borerinfested regions: a test of tree-level, hyperspectral technologies. Remote Sens Environ 112(5):2665-2676. https://doi.org/10.1016/j.rse.2007.12.011

Pontius J, Halman JM, Schaberg PG (2016) Seventy years of forest growth and community dynamics in an undisturbed northern hardwood forest. Can J For Res 46(7):959-967. https:// doi.org/10.1139/cjfr-2015-0304

Pontius J, Hanavan RP, Hallett RA, Cook BD, Corp LA (2017) High spatial resolution spectral unmixing for mapping ash species across a complex urban environment. Remote Sens Environ 199:360-369

Porter WM, Enmark HT (1987) A system overview of the airborne visible/infrared imaging spectrometer (AVIRIS). In: Imaging Spectroscopy II, vol 834. International Society for Optics and Photonics, Bellingham, WA. pp 22-32

Qi J, Chehbouni A, Huete AR, Kerr YH, Sorooshian S (1994) A modified soil adjusted vegetation index. Remote Sens Environ 48(2):119-126. https://doi.org/10.1016/0034-4257(94)90134-1

Rahman AF, Gamon JA, Fuentes DA, Roberts DA, Prentiss D (2001) Modeling spatially distributed ecosystem flux of boreal forest using hyperspectral indices from AVIRIS imagery. J Geophys Res-Atmos 106(D24):33579-33591

Rock BN, Vogelmann AF, Williams DL, Vogelmann DL, Hoshizaki T (1986) Remote detection of forest damage. Bioscience 36(7):439-445

Rock BN, Hoshizaki T, Miller JR (1988) Comparison of in situ and airborne spectral measurements of the blue shift associated with forest decline. Remote Sens Environ 24(1):109-127

Rondeaux G, Steven M, Baret F (1996) Optimization of soil-adjusted vegetation indices. Remote Sens Environ 55(2):95-107. https://doi.org/10.1016/0034-4257(95)00186-7

Roujean J-L, Breon F-M (1995) Estimating PAR absorbed by vegetation from bidirectional reflectance measurements. Remote Sens Environ 51(3):375-384

Rouse J, Hass R, Schell J, Deering D, Harlan J (1974) Monitoring the vernal advancement and retrogradation of natural vegetation. NASA Report, Greenbelt, MD

Schaberg PG, Dehayes DH, Hawley GJ (2001) Anthropogenic calcium depletion: a unique threat to forest ecosystem health? Ecosyst Health 7(4):214-228 
Schaberg PG, Minocha R, Long S, Halman JM, Hawley GJ, Eagar C (2011) Calcium addition at the Hubbard Brook Experimental Forest increases the capacity for stress tolerance and carbon capture in red spruce (Picea rubens) trees during the cold season. Trees 25(6):1053-1061

Schaberg PG, Murakami PF, Butnor JR, Hawley GJ (2017) Experimental branch cooling increases foliar sugar and anthocyanin concentrations in sugar maple at the end of the growing season. Can J For Res 47(5):696-701

Senf C, Seidl R, Hostert P (2017) Remote sensing of forest insect disturbances: current state and future directions. Int J Appl Earth Obs Geoinf 60:49-60

Serbin SP, Singh A, McNeil BE, Kingdon CC, Townsend PA (2014) Spectroscopic determination of leaf morphological and biochemical traits for northern temperate and boreal tree species. Ecol Appl 24(7):1651-1669

Serbin SP, Singh A, Desai AR, Dubois SG, Jablonski AD, Kingdon CC et al (2015) Remotely estimating photosynthetic capacity, and its response to temperature, in vegetation canopies using imaging spectroscopy. Remote Sens Environ 167:78-87

Sims DA, Gamon JA (2002) Relationships between leaf pigment content and spectral reflectance across a wide range of species, leaf structures and developmental stages. Remote Sens Environ 81(2-3):337-354

Singh A, Serbin SP, McNeil BE, Kingdon CC, Townsend PA (2015) Imaging spectroscopy algorithms for mapping canopy foliar chemical and morphological traits and their uncertainties. Ecol Appl 25(8):2180-2197

Sitzia T, Campagnaro T, Kowarik I, Trentanovi G (2016) Using forest management to control invasive alien species: helping implement the new European regulation on invasive alien species. Biol Invasions 18(1):1-7

Sivanpillai R, Smith CT, Srinivasan R, Messina MG, Ben Wu X (2006) Estimation of managed loblolly pine stand age and density with Landsat ETM+ data. For Ecol Manag 223(1-3):247254. https://doi.org/10.1016/j.foreco.2005.11.013

Smith ML, Ollinger SV, Martin ME, Aber JD, Hallett RA, Goodale CL (2002) Direct estimation of aboveground forest productivity through hyperspectral remote sensing of canopy nitrogen. Ecol Appl 12(5):1286-1302

Strimbeck GR, Schaberg PG, Fossdal CG, Schröder WP, Kjellsen TD (2015) Extreme low temperature tolerance in woody plants. Front Plant Sci 6:884

Thenkabail PS, Mariotto I, Gumma MK, Middleton EM, Landis DR, Huemmrich KF (2013) Selection of hyperspectral narrowbands (HNBs) and composition of hyperspectral twoband vegetation indices (HVIs) for biophysical characterization and discrimination of crop types using field reflectance and Hyperion/EO-1 data. IEEE J-STARS 6(2):427-439

Thompson I, Mackey B, McNulty S, Mosseler A (2009) Forest resilience, biodiversity, and climate change. In secretariat of the convention on biological diversity, Montreal. Technical Series No. 43. Vol 43, pp 1-67

Tomback DF, Achuff P (2010) Blister rust and western forest biodiversity: ecology, values and outlook for white pines. For Pathol 40(3-4):186-225

Townsend PA, Foster JR, Chastain RA, Currie WS (2003) Application of imaging spectroscopy to mapping canopy nitrogen in the forests of the central appalachian mountains using hyperion and aviris. IEEE Trans Geosci Remote Sens 41(6):1347-1354

Tucker CJ (1979) Red and photographic infrared linear combinations for monitoring vegetation. Remote Sens Environ 8:127-150

Vogelmann JE, Rock BN, Moss DM (1993) Red edge spectral measurements from sugar maple leaves. Int J Remote Sens 14(8):1563-1575

White K, Pontius J, Schaberg P (2014) Remote sensing of spring phenology in northeastern forests: a comparison of methods, field metrics and sources of uncertainty. Remote Sens Environ 148:97-107. https://doi.org/10.1016/j.rse.2014.03.017

Williams AP, Hunt ER (2002) Estimation of leafy spurge cover from hyperspectral imagery using mixture tuned matched filtering. Remote Sens Environ 82(2-3):446-456

Williams P, Norris K (2001) Near-infrared Technology in the Agricultural and Food Industries. American Association of Cereal Chemists, Inc., St. Paul 
Williams DL, Goward S, Arvidson T (2006) Landsat. Photogramm Eng Remote Sens 72(10):1171-1178

Zarco-Tejada PJ, Miller JR, Mohammed GH, Noland TL, Sampson PH (2002) Vegetation stress detection through chlorophyll $a+b$ estimation and fluorescence effects on hyperspectral imagery. J Environ Qual 31(5):1433-1441

Zarco-Tejada PJ, Hornero A, Hernández-Clemente R, Beck PSA (2018) Understanding the temporal dimension of the red-edge spectral region for forest decline detection using high-resolution hyperspectral and sentinel-2a imagery. ISPRS J Photogramm Remote Sens 137:134

Open Access This chapter is licensed under the terms of the Creative Commons Attribution 4.0 International License (http://creativecommons.org/licenses/by/4.0/), which permits use, sharing, adaptation, distribution and reproduction in any medium or format, as long as you give appropriate credit to the original author(s) and the source, provide a link to the Creative Commons license and indicate if changes were made.

The images or other third party material in this chapter are included in the chapter's Creative Commons license, unless indicated otherwise in a credit line to the material. If material is not included in the chapter's Creative Commons license and your intended use is not permitted by statutory regulation or exceeds the permitted use, you will need to obtain permission directly from the copyright holder. 